\title{
Petrografia, química mineral e geoquímica de filossilicatos como indicadores da proveniência dos sedimentos neoproterozoicos das formações Serra de Santa Helena e Serra da Saudade (Grupo Bambuí)
}

\author{
(este artigo contem material suplementar disponível na versão eletrônica)
}

\section{Laura Flores Brant CAMPOS ${ }^{1} \&$ Edi Mendes GUIMARÃES ${ }^{2}$}

\author{
Programa de Pós-graduação em Geociências, Instituto de Geociências, Universidade de Brasília. Campus Darcy Ribeiro, Ala \\ Central, CEP 70.910-900, Brasília, DF, Brasil (laurafbrant@gmail.com). \\ 2 Laboratório de Difração de Raios X, Instituto de Geociências, Universidade de Brasília. Campus Darcy Ribeiro, Ala Central, \\ CEP 70.910-900, Brasília, DF, Brasil (rxedi@unb.br).
}

Campos, L.F.B. \& Guimarães, E.M. 2018. Petrografia, química mineral e geoquímica de filossilicatos como indicadores da proveniência dos sedimentos neoproterozoicos das formações Serra de Santa Helena e Serra da Saudade (Grupo Bambuí). Pesquisas em Geociências, 45: e0707. DOI: https://doi.org/10.22456/1807-9806.91388

\begin{abstract}
Resumo. A caracterização mineral e geoquímica de pelitos das formações Serra de Santa Helena (FSSH) e Serra da Saudade (FSS) podem contribuir para a interpretação da evolução da bacia de deposição do Grupo Bambuí, que tem sido considerada como do tipo foreland relacionada à Orogênese Brasiliana. Assim, este trabalho visa comparar a composição dos pelitos ao longo da coluna estratigráfica - FSSH e FSS - e na distribuição geográfica entre as regiões de Vila Boa - Bezerra, a oeste, e da Serra de São Domingos, a leste, buscando indicações sobre condições deposicionais e a proveniência dos sedimentos. Para isto foram realizadas análises petrográficas, por difração de raios X, geoquímica de rocha total e química mineral de filossilicatos. Verifica-se que na FSSH a oeste há maior variação de estruturas sedimentares, composição mineral e composição química do que a leste, enquanto que na FSS os pelitos tendem a maior homogeneidade além de conter maior contribuição de minerais ferromagnesianos, representados por clorita e biotita. Em ambas as formações é confirmada a seleção granulométrica, em que os pelitos mais finos são constituídos essencialmente por filossilicatos enquanto os mais grossos contêm maior porcentagem de silicatos não argilosos, principalmente albita. Valores do Índice de Variação Composicional (IVC) na FSSH e na FSS indicam sedimentos imaturos nas duas unidades tanto a oeste quanto a leste, mas valores distintos refletem variação da rocha fonte. Na FSSH a oeste há também pelitos mais maturos, com contribuição de sedimentos reciclados provenientes do Grupo Paranoá (glauconita e zircão). Esses sedimentos imaturos, com IVC em torno de 1, tendem a ser encontrados em áreas tectonicamente ativas, provavelmente associadas à evolução da Faixa de Dobramentos Brasília.
\end{abstract}

Palavras-chave. Pelitos, feições deposicionais, Índice de Variabilidade Composicional.

\begin{abstract}
PETROGRAPHY, MINERAL CHEMISTRY AND GEOCHEMISTRY OF PHYLLOSSILICATES AS INDICATORS OF THE PROVENANCE OF THE NEOPROTEROZOIC SEDIMENTS OF THE SERRA DE SANTA HELENA AND SERRA DA SAUDADE FORMATIONS (BAMBUÍ GROUP). The mineral and geochemical characterization of pelites of the Serra de Santa Helena (FSSH) and Serra da Saudade (FSS) formations may contribute to the interpretation of the evolution of the Bambuí Group deposition basin, which has been considered as a foreland type related to Brazilian Orogenenesis. This work aims to compare the composition of the pelites along the stratigraphic column - FSSH and FSS - and the geographical distribution between the regions of Vila Boa - Bezerra to the west and the Serra de São Domingos to the east, looking for indications of conditions sedimentation. For this, petrographic analyzes were carried out by X-ray diffraction, total rock geochemistry and mineral chemistry of phyllossilicates. It is observed that in the FSSH to the west there is a greater variation of sedimentary structures, mineral composition and chemical composition than in the east, while in the FSS the pelites tend to have greater homogeneity besides containing greater contribution of ferromagnesian minerals, represented by chlorite and biotite. In both formations the granulometric selection is confirmed, in which the finest pelites are constituted essentially by phyllosilicates while the coarser ones contain a greater percentage of non-clayey silicates, mainly albite. The values of the Index of Compositional Variability (ICV) in the FSSH and the FSS indicate immature sediments in the two units both west
\end{abstract}


and east, but distinct values reflect variation of the source rock. In the FSSH to the west there are also more mature pellets, with contribution of recycled sediments from the Paranoá Group (glauconite and zircon). These immature sediments, with ICV around 1, tend to be found in tectonically active areas, probably associated to the evolution of the Brasilia Folding Range.

Keywords. Pelites, depositional features, Compositional Variability Index.

\section{Introdução}

Na região do Distrito Federal e seu entorno estão expostas rochas sedimentares dos grupos Paranoá e Bambuí, de idades meso e neoproterozoicas, respectivamente. Localmente, estes grupos são recobertos pela sequência metassedimentar do Grupo Canastra, através de falha de empurrão, gerada durante a Orogênese Brasiliana (Fuck, 1994; Fuck et al., 1994; Valeriano et al., 2004). Este evento marca o final da deposição sobre margem passiva dos sedimentos maturos - quase inteiramente quartzo e illita, com escasso feldspato potássico - do Grupo Paranoá (Alvarenga \& Dardenne, 1978; Laranjeira \& Dardenne, 1993; Guimarães, 1997), atribuídos à área-fonte de composição sílico-aluminosa. Sedimentos de composição mais ferro-magnesiana com importante contribuição de cloritas associadas a quartzo, illita e albita, constituem as rochas siliciclásticas do Grupo Bambuí, indicando a instalação de nova área-fonte, relacionada à Orogênese Brasiliana (Alkmin et al., 1993; Guimarães, 1997; Alkmin \& Martins-Neto, 2001; Dardenne et al., 2003), inclusive o Arco Magmático de Goiás (Pimentel et al., 2001).

Os termos siliciclásticos ocorrem como folhelhos associados a rochas carbonáticas das formações Sete Lagoas e Lagoa do Jacaré, ou são constituintes tanto de pelitos e arenitos muito finos das formações Serra de Santa Helena e Serra da Saudade, bem como arenitos subquartzosos da Formação Três Marias.

As formações Serra de Santa Helena (FSSH) e Serra da Saudade (FSS) afloram nos estados de Minas Gerais, Goiás, Bahia e Tocantins, incluindo áreas do Distrito Federal. Essas unidades variam de espessura da ordem de algumas dezenas até várias centenas de metros ao longo de toda a extensão da bacia.

A persistência ou variações na composição mineral e/ou nas características geoquímicas refletem as condições deposicionais e a proveniência dos sedimentos. Um parâmetro utilizado é o Índice de Variação Composicional - IVC - (ICV; Index of Compositional Variability) que mede a abundância de alumínio relativo a outros cátions maiores na rocha, refletindo a maturidade composicional em pelitos (Cox et al., 1995). Os pelitos composicionalmente imaturos tendem a ser encontrados em ambientes tectonicamente ativos enquanto os maturos caracterizam ambientes quiescentes tectonicamente ou cratônicos (Cox et al., 1995).

Assim, a caracterização mineral e geoquímica de rochas e minerais das formações SSH e SS podem contribuir para a interpretação da evolução da bacia de deposição do Grupo Bambuí, que tem sido considerada como do tipo foreland relacionada à Orogênese Brasiliana (Alkmin et al., 1993; Guimarães, 1997; Alkmin \& Martins-Neto, 2001; Dardenne et al., 2003).

Campos \& Guimarães (2017) identificaram variações na composição geoquímica conforme a região amostrada utilizando porcentagem de óxidos e teores de elementos traço. 0 presente trabalho tem por objetivo comparar a composição dos pelitos e arenitos muito finos tanto ao longo da coluna estratigráfica - formações SSH e SS - como na distribuição geográfica entre as regiões de Vila Boa - Bezerra, a oeste, e da Serra de São Domingos, a leste, buscando indicações sobre condições deposicionais e a proveniência dos sedimentos. Para isto foram realizadas análises petrográficas, por difração de raios $\mathrm{X}$, geoquímica de rocha total e química mineral de filossilicatos, indicativos principalmente da rocha fonte.

\section{2 Área, materiais e métodos}

Os dados apresentados neste trabalho se referem ao estudo de amostras pertencentes às formações FSSH e FSS do Grupo Bambuí (Fig. 1A), coletadas nas localidades de Vila Boa e Bezerra (GO) e na Serra de São Domingos (MG), conforme Fig. $1 \mathrm{~B}$. 


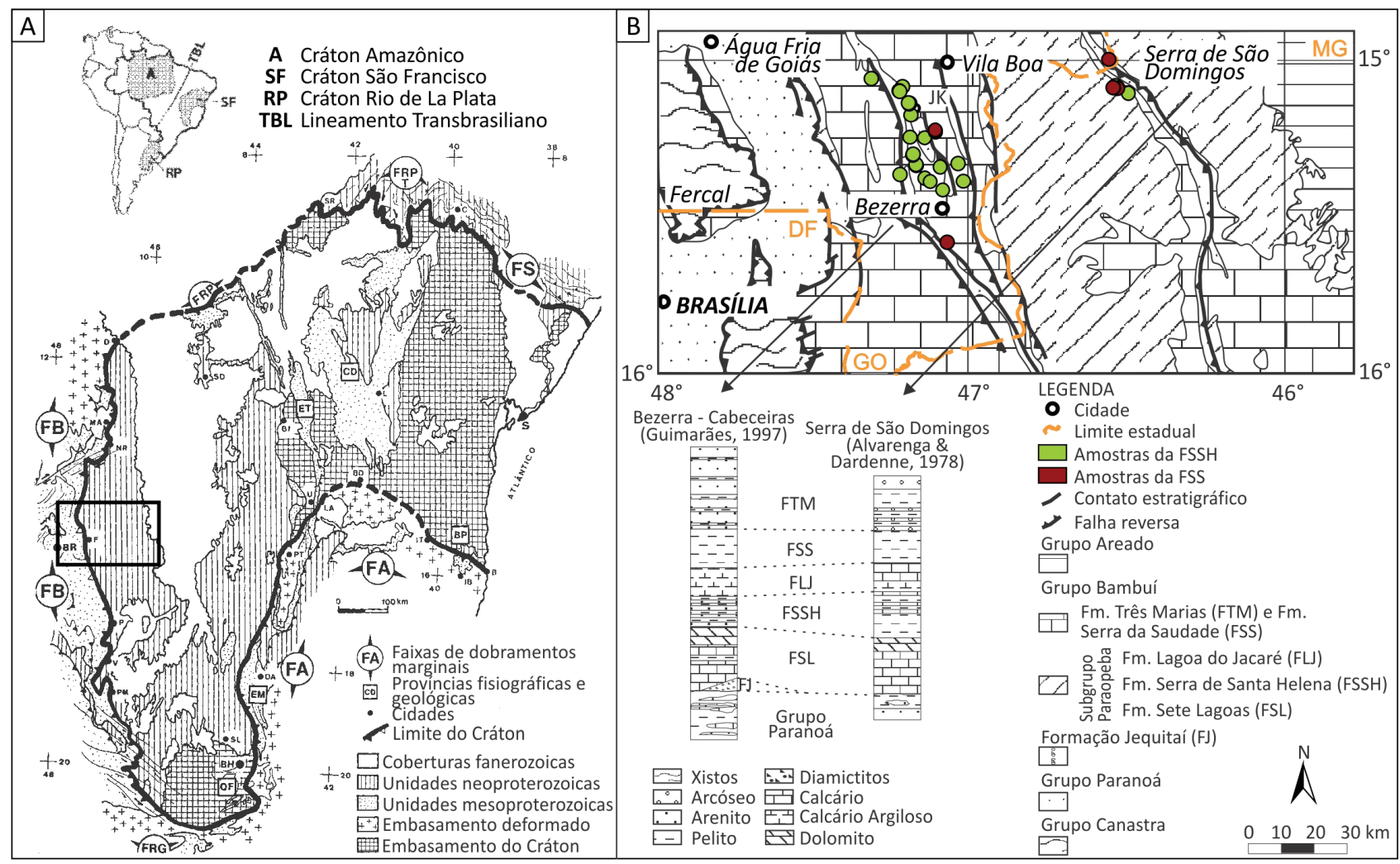

Figura 1. Contexto geológico. A) Limites do Cráton do São Francisco com indicação das bacias Neoproterozóicas e faixas móveis (modificado de Alkmin et al., 1993). Cidades: SR: São Raimundo Nonato, C: Curaçá, D: Dianópolis, SD: São Desidério, L: Lençois, MA: Monte Alegre de Goiás, BJ: Bom Jesus da Lapa, S: Salvador, NR: Nova Roma, BD: Brumado, U: Urandi, LA: Licínio de Almeida, F: Formosa, IT: Itapetinga, BR: Brasília, B:Belmonte, PT: Porteirinha, IB: Itapebí, P: Paracatu, V: Vazante, DA: Diamantina, P: Patos de Minas, SL: Sete Lagoas, BH: Belo Horizonte; Províncias fisiográficas e geológicas: CD: Chapada Diamantina, ET: Espinhaço Setentrional, BP: Bacia do Rio do Pardo, EM: Espinhaço Meridional, QF: Quadrilátero Ferrífero; Faixas de dobramentos marginais, brasilianas: FA: Faixa Araçuaí, FRG: Faixa Alto Rio Grande, FB: Faixa Brasília, FRP: Faixa Rio Preto, FRPT: Faixa Riacho do Pontal, FS: Faixa Sergipana. B) Mapa geológico simplificado segundo Pinto \& Silva (2014) com a localização das amostras e colunas estratigráficas.

Figure 1. Geologic setting. A) Border of São Francisco Craton with indication of the Neoproterozoic basins and moving bands (Alkmin et al., 1993). Cities: SR: São Raimundo Nonato, C: Curaçá, D: Dianópolis, SD: São Desidério, L: Lençois, MA: Monte Alegre de Goiás, BJ: Bom Jesus da Lapa, S: Salvador, NR: Nova Roma, BD: Brumado, U: Urandi, LA: Licínio de Almeida, F: Formosa, IT: Itapetinga, BR: Brasília, B:Belmonte, PT: Porteirinha, IB: Itapebí, P: Paracatu, V: Vazante, DA: Diamantina, P: Patos de Minas, SL: Sete Lagoas, BH: Belo Horizonte; Physiographic and geological provinces: CD: Chapada Diamantina, ET: Espinhaço Setentrional, BP: Bacia do Rio do Pardo, EM: Espinhaço Meridional, QF: Quadrilátero Ferrífero; Marginal Brazilian folding bands: FA: Faixa Araçuaí, FRG: Faixa Alto Rio Grande, FB: Faixa Brasília, FRP: Faixa Rio Preto, FRPT: Faixa Riacho do Pontal, FS: Faixa Sergipana. B) Simplified geological map after Pinto \& Silva (2014) with sample location and stratigraphic columns.

\subsection{Contexto Geológico dos pontos estudados: Grupo Bambuí}

O Grupo Bambuí, do Final do Neoproterozoico, recobre parcialmente o Cráton São Francisco e se estende à porção oriental da Faixa de Dobramentos Brasília - FDB - (Fuck et al., 1994; Fuck, 1994; Fig. 1A).

Estudos em pelitos indicam condições de anquizona, especialmente próximo à falha de empurrão que, no norte do Distrito Federal, sobrepõe o Grupo Canastra aos grupos Paranoá e Bambuí (Campos, 2012; Campos et al., 2015).

o Grupo Bambuí corresponde a uma suces- são pelito-carbonatada (Fig. 1B; Dardenne, 1978, 2000), formada na base pelo Subgrupo Paraopeba - formações Sete Lagoas (FSL), Serra de Santa Helena (FSSH) e Lagoa do Jacaré (FLJ) - o qual é sobreposto pelas formações Serra da Saudade (FSS) e Três Marias (FTM).

As formações FSL e FLJ são constituídas por rochas carbonáticas e pelíticas, sobrepostas por contato abrupto, respectivamente pelas formações FSSH e FSS, de composição predominantemente siliciclástica (Dardenne, 1978; Alvarenga \& Dardenne, 1978).

A FSSH é constituída por pelitos cinza escuros, além de arenitos finos e, raramente, médios, 
e de camadas submétricas de calcário cinza escuro, por vezes cristalino, na base. Tanto os pelitos como os arenitos são, em geral, subquartzosos constituídos por quartzo, filossilicatos e feldspato, predominantemente plagioclásio (Guimarães, 1997; Campos et al., 2015; Sampaio, 2016). Esta é também a composição dos arenitos, que são bem selecionados, com grãos planares orientados segundo o acamamento e podem apresentar cimento calcítico. Grãos líticos são constituídos por biotita, clorita, quartzo e minerais opacos, ou representam rocha sedimentar pelítica. Além dos constituintes traço (minerais opacos, turmalina, epidoto, zircão e glauconita) o material fino constituído por minerais opacos e filossilicatos compõem menos que 15\% de pseudomatriz (Guimarães, 1997; Guimarães et al., 2004).

A FSS é também formada por pelitos e ritmitos silto-arenosos, de coloração cinza escuro a esverdeado, tendo composição mineral semelhante à FSSH. Localmente contem pelitos verdes - verdetes - caracterizados pelo alto conteúdo de $\mathrm{K}_{2} \mathrm{O}$ (> $5 \%$ ) e $\mathrm{P}_{2} \mathrm{O}_{5}(>3 \%)$ (Dardenne, 1978; Lima, 2005; Lima et al., 2007; Moreira et al., 2016).

\subsection{Materiais}

As amostras provenientes das formações FSSH e FSS são pelitos de cores que variam entre cinza escuros a cinza esverdeado contendo localmente grãos tamanho areia e eventualmente contribuição carbonática. Frequentemente ocorrem intercalações de arenitos, com camadas que variam de espessura milimétrica a decimétrica e, especialmente na FSSH, há intercalação de camadas de até cerca de $20 \mathrm{~cm}$ de arenito fino.

Foram coletadas 30 amostras de argilitos/ folhelhos, siltitos e arenitos muito finos destas formações em afloramentos de escarpas, ao longo de drenagens e em cortes de estrada em Vila Boa - Bezerra e na Serra de São Domingos (Fig. 1B) e tabela 1 (vide material suplementar).

\subsection{Métodos}

Para fazer a caracterização mineral e química foram utilizadas as técnicas convencionais dos laboratórios do Instituto de Geociências da UnB
(IG/UnB). As lâminas delgadas foram preparadas e confeccionadas no Laboratório de Laminação (LABLAM). Essas lâminas foram utilizadas para descrição petrográfica, análises de microscopia eletrônica de varredura e microanálises por sonda eletrônica, que foram feitas respectivamente nos laboratórios de Microscopia Eletrônica de Varredura (LMEV) e de Microssonda Eletrônica (LASON). Amostras frescas foram desagregadas no Laboratório de Difratometria de raios X (LDRX) utilizando-se o moinho da Marca FRITSCH Modelo Pulverisette 5 e foram utilizadas para análises difratométricas, realizadas no próprio laboratório, e análises geoquímicas de rocha total, foram realizadas no Laboratório de Geocronologia/UnB, no Centro Regional para o Desenvolvimento Tecnológico e Inovação (CRTI/UFG) e no SGS Geosol Laboratórios.

\subsubsection{Análises petrográficas}

Foram analisadas 24 lâminas delgadas de pelitos e arenitos muito fino das formações FSSH e FSS. Devido à fina granulometria das rochas, a análise microscópica foi utilizada prioritariamente para o detalhamento das estruturas sedimentares, diagenéticas e tectônicas.

Com o objetivo de complementar a descrição petrográfica, 8 lâminas delgadas foram analisadas por microscopia eletrônica de varredura, utilizando-se o equipamento da marca FEI modelo Quanta 450, EDS da EDAX, com corrente de 20 a 30 kV, distância de trabalho de 11,7 e 11,8 mm e spot de 5,0 a 6,0 $\mu \mathrm{m}$. Para visualização utilizou-se o software TEAM viewer.

\subsubsection{Análises difratométricas}

Para identificação de minerais, 30 amostras foram analisadas. Os fragmentos de rocha $<20 \mathrm{~mm}$ foram triturados e pulverizados no moinho de bola a $300 \mathrm{rpm}$ por $5 \mathrm{~min}$. Após essa pulverização da rocha total $(\mathrm{T})$, o material foi compactado a seco sobre lâmina de vidro.

A fração argila foi obtida a partir do sobrenadante resultante da dispersão da amostra pulverizada em água destilada seguida de centrifugação a 750 rpm por 7 min. 0 sobrenadante é então centri- 
fugado por 30 minutos a 3000 rpm para decantar a fração argila, utilizada para a preparação das lâminas orientadas, pela técnica do esfregaço.

Após secar em temperatura ambiente $(\mathrm{N})$, as lâminas orientadas das frações $<2 \mu \mathrm{m}$ foram analisadas e em seguida solvatadas com etileno-glicol em atmosfera de vácuo por 12 horas (G). Posteriormente, essas lâminas foram aquecidas (A) a $490-500^{\circ} \mathrm{C}$ em uma mufla N480D da Fornos Magnus, por um período de quatro horas.

As amostras foram analisadas em equipamento RIGAKU, modelo ULTIMA IV, operando com tubo de cobre e filtro de níquel, sob voltagem de 35 $\mathrm{kV}$ e corrente de $15 \mathrm{~mA}$, velocidade da varredura de $2^{\circ} /$ minuto, passos de $0,05^{\circ}$. As análises foram realizadas no intervalo $2 \theta$ de $2^{\circ}$ a $80^{\circ}$ para a amostra total, de $2^{\circ}$ a $65^{\circ}$ para as frações argila secas ao ar e solvatadas com etileno-glicol, e de $2^{\circ}$ a $40^{\circ}$ para amostras aquecidas (A).

A identificação dos minerais foi feita por meio do programa JADE 9.0, base Windows, com banco de dados PC-PDF (Powder Diffraction File PDF para PC/ICDD) e a proporção dos constituintes foi feita comparando-se as reflexões do quartzo em d 4,26 ̊̊ com as da albita em d 3,19 $\AA$, da muscovita/illita em $\mathrm{d} \sim 10 \AA$ e da clorita em $\mathrm{d} \sim 14$ A. As reflexões maiores que as do quartzo foram atribuídas a constituintes maiores, as menores até a altura da metade da reflexão do quartzo, constituintes menores e as menores do que a metade da reflexão do quartzo, constituintes traço.

\subsubsection{Análises geoquímicas de rocha total}

Os óxidos majoritários $-\mathrm{SiO}_{2}, \mathrm{Al}_{2} \mathrm{O}_{3}, \mathrm{Fe}_{2} \mathrm{O}_{3}$, $\mathrm{CaO}, \mathrm{MgO}, \mathrm{TiO}_{2}, \mathrm{P}_{2} \mathrm{O}_{5}, \mathrm{Na}_{2} \mathrm{O}, \mathrm{K}_{2} \mathrm{O}, \mathrm{MnO}$ - foram determinados por Fluorescência de raios $X$ (FRX) em 40 amostras de pelitos, sendo 8 analisadas no Laboratório de Geocronologia/UnB, 7 no CRTI/UFG e 25 no SGS Geosol Laboratórios.

\subsubsection{Química Mineral}

Para determinar a química mineral das micas e clorita, 11 lâminas delgadas foram analisadas por sonda eletrônica utilizando-se o equipamento JEOL modelo JXA-8230, voltagem de $15 \mathrm{kV}$, corrente de $1,5 \mathrm{~mA}$, tempo de contagem de 10 a 20 segun- dos, conforme o elemento, e o foco de aproximadamente $1 \mu \mathrm{m}$.

Os resultados das análises, dados em porcentagem de óxidos, foram normalizados para $\mathrm{O}_{20}(\mathrm{OH})_{4}$, resultando em carga total negativa igual a 44, e para $\mathrm{O}_{20}(\mathrm{OH})_{16}$, carga total negativa igual a 56, a fim de obter a fórmula estrutural de micas e clorita, respectivamente. $\mathrm{O}$ ferro, obtido como FeO, foi assumido como $\mathrm{Fe}_{2} \mathrm{O}_{3}$ para o cálculo das micas dioctaédricas e illita ao passo que para as micas trioctaédricas e cloritas, como FeO, conforme composição ideal desses minerais.

Foram aceitas como análises válidas, para micas dioctaédricas fórmula unitária com valores de Si entre 6,0 e 7, soma do octaedro de 3,8 a 4,0, e soma de álcalis próxima a 2,0 para micas dioctaédricas. Valores de Si mais altos, até um limite em torno de 7,7, soma do octaedro de 3,5 a 4,0, sendo que o Al é maior que 3,0, e soma de álcalis inferior a 2,0, até 1,5 para illita; Si entre 6,0 e 7,0, soma do octaedro entre 5,0 e 6,0 e soma de álcalis até 2,0, para micas trioctaédricas; e, Si entre 5,0 e 7,0 e soma do octaedro entre 10,0 e 12,0 para cloritas.

A interpretação dos dados foi feita com o auxílio de diagramas binários e ternários produzidos no software PETROGRAPH (Petrelli et al., 2005).

\section{Resultados}

Os resultados das análises petrográficas, difratométricas, geoquímicas e de química mineral mostram que os pelitos das formações Serra de Santa Helena e Serra da Saudade apresentem feições sedimentares comuns, bem como semelhança da composição mineral, particularmente dos filossilicatos. Entretanto, algumas diferenças texturais e composicionais são identificadas na mesma unidade entre as regiões de Vila Boa - Bezerra (oeste) e Serra de São Domingos (leste) e entre FSSH e FSS.

\subsection{Características gerais das rochas}

Estas características são definidas em amostras de mão, em lâminas petrográficas, difração de raios $\mathrm{X}$ e análises geoquímicas. 


\subsubsection{Petrografia e difração de raios $X$}

No geral, as amostras analisadas são pelitos, sendo os siltitos mais grossos pertencentes à FSSH, com até $25 \%$ de grãos tamanho areia fina, enquanto os da FSS são constituídos por no máximo 10\%.

Os pelitos das duas unidades geralmente são homogêneos e apresentam predominantemente estruturas de decantação por vezes intercaladas a estruturas de fluxo (Fig. 2) e tabela 2 (vide material suplementar). Podem ser maciços ou laminados: com laminação incipiente paralela e subparalela indicada pela orientação de filossilicatos e de opacos, ou com laminação forte, evidenciada pela alternância de composição ou microgradação.

Na maioria das amostras analisadas, o tamanho de grão modal é silte. Enquanto na FSSH os grãos são moderadamente a mal selecionados e subangulosos a muito angulosos, na FSS os grãos são moderadamente a bem selecionados e subangulosos a angulosos. Em ambas as formações há indícios de corrosão das bordas dos grãos detríticos de quartzo e de feldspatos.

Quanto à composição mineral, por microscopia ótica, os pelitos das duas formações são subquartzosos constituídos por muscovita/illita, biotita e clorita, seguidos de feldspatos, material opaco e vermiculita além de material fino não identificado (MFNI) em proporções variáveis enquanto calcita ocorre em pelitos com contribuição carbonática (tabelas 3 e 4 - vide material suplementar). Nos pelitos da FSSH, são identificados também glauconita e zircão.

Devido ao alto conteúdo de MFNI, utilizouse a DRX para auxiliar a identificação dos minerais. Em amostra total de ambas as formações, quartzo é constituinte maior, albita constituinte menor, feldspato potássico e calcita ocorrem eventualmente como constituintes traço, sendo variável a quantidade de filossilicatos. Rutilo e vermiculita ocorrem nos pelitos das duas formações, mas hematita e pirita são identificados por DRX como constituintes traços exclusivamente na FSSH.

Com base na porcentagem de MFNI e filossilicatos descritos por petrografia e nas intensidades nos difratogramas das reflexões do quartzo, em d= 4,26 ̊, e da albita, em d= 3,19 ̊, comparadas com as reflexões em $d=5,0 \AA$ e $4,74 \AA$, características respectivamente de micas e cloritas, foram discriminados dois grupos - I e II - compreendendo as análises com as reflexões mais e menos intensas.

No grupo I (Fig. 3) e tabela 3 (vide material suplementar), mica/illita e clorita são constituintes menores ou até maiores na amostra total, quartzo é constituinte maior e albita, constituinte menor. Na fração argila, predominam os filossilicatos, isto é, diminui a quantidade relativa de quartzo e albita, indicada pelas reflexões $d=4,26 \AA$ e $3,19 \AA$ menos intensas que $d=5,0 \AA$ e $4,74 \AA$ de mica e clorita.

No Grupo II (Fig. 4) e tabela 4 (vide material suplementar), mica/illita e clorita são constituintes menores ou traço na amostra total e embora haja um aumento nas suas proporções na fração argila, o quartzo e a albita ainda predominam, já que suas reflexões - respectivamente $d=4,26 \AA$ e $3,19 \AA$ - são mais intensas que dos filossilicatos (d = 5,0 ̊ e 4,74 ̊̊).

A maioria dos difratogramas mostra a predominância de análises do Grupo I, o que pode ser explicado pela granulometria fina dos pelitos da FSSH e da FSS, tanto na porção oeste, quanto leste. As análises do Grupo II correspondem quase exclusivamente a amostras da FSSH, com níveis de granulometria um pouco maior, contendo grãos de areia fina. Raras amostras da FSS foram registradas neste grupo, coerente com sua granulometria mais fina.

\subsubsection{Análises geoquímicas de rocha total}

Pelas análises geoquímicas, podem ser identificados dois conjuntos distintos de amostras, considerando o conteúdo de $\mathrm{SiO}_{2}$ : um deles com valores abaixo de $70 \%$ e outro acima deste percentual, tabela 5 (vide material suplementar). Esses conjuntos correspondem aos grupos I e II definidos por petrografia e DRX com exceção das amostras M012-IX-36 e EGSD-12, que estão no grupo II mas tem $\mathrm{SiO}_{2}$ inferior a $70 \%$.

O conjunto menos silicoso (Fig. 5), no qual a maioria dos valores de $\mathrm{Na}_{2} \mathrm{O}$ está abaixo de $2 \%$, é também o que tem os maiores de $\mathrm{Al}_{2} \mathrm{O}_{3}$ (de $13 \%$ até mais que $17 \%$ ), $\mathrm{Fe}_{2} \mathrm{O}_{3}$ acima de $5 \%$, enquanto para $\mathrm{MgO}$ e $\mathrm{K}_{2} \mathrm{O}$ predominam valores maiores que $2 \%$. A soma de $\mathrm{Fe}_{2} \mathrm{O}_{3}$ e $\mathrm{MgO}$ tende a $10 \%$, registra- 


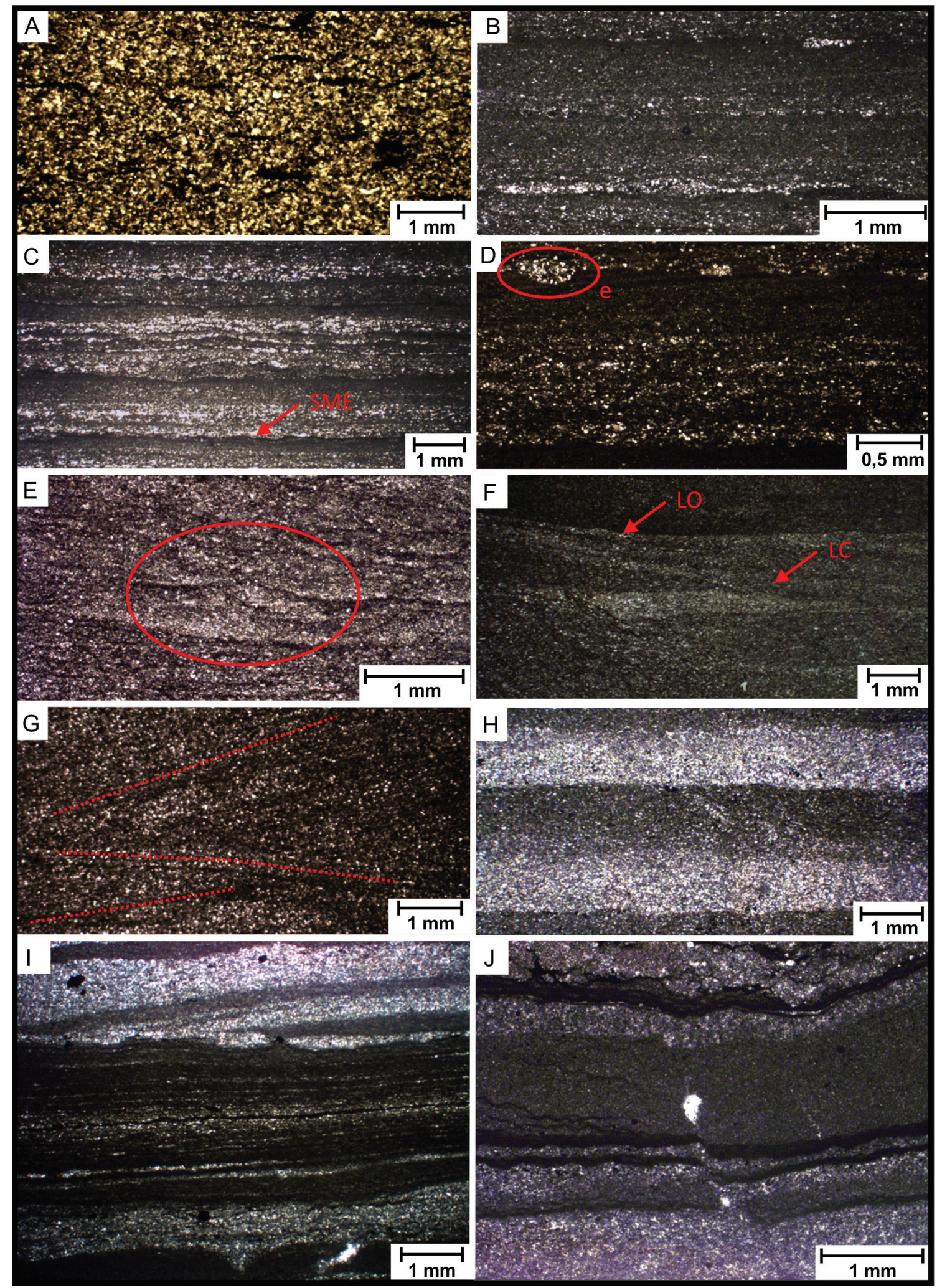

Figura 2. Fotomicrografia com nicois paralelos das principais estruturas observadas em pelitos das formações FSSH e FSS. A) Laminação paralela incipiente evidenciada por filmes de opacos; B) Estrutura lenticular; C) Laminação plano-paralela e superfície irregular: microerosão ou em chama (?); D) Microgradação incipiente e estrutura de escavação (e); E) Laminação irregular, estrutura flaser e estrutura escape de fluido; F) Laminações cruzada (LC) e ondulada (LO); G) Laminação cruzada incipiente; H) Microgradação e laminação plano-paralela; I) Ritmito com estrutra lenticular de silte e laminação por decantação; J) Microfalha sin-sedimentar.

Figure 2. Photomicrography with polars crossed of the main structures observed in pelites of the FSSH and FSS formations. A) Incipient parallel lamination evidenced by opaque films; B) Linsen structure; C) Flat-parallel lamination and irregular surface: microerosion or flame (?); D) Incipient micrograding and excavation structure (e); E) Irregular lamination, flaser and fluid-escape structures; F) Cross-lamination (LC) and wavy-lamination (LO); G) Incipient cross-lamination; H) Microgradation and flat-parallel lamination; I) Rhythmite with linsen structure from siltstone and suspension-settling lamination; D) Sin-sedimentary microfault. 


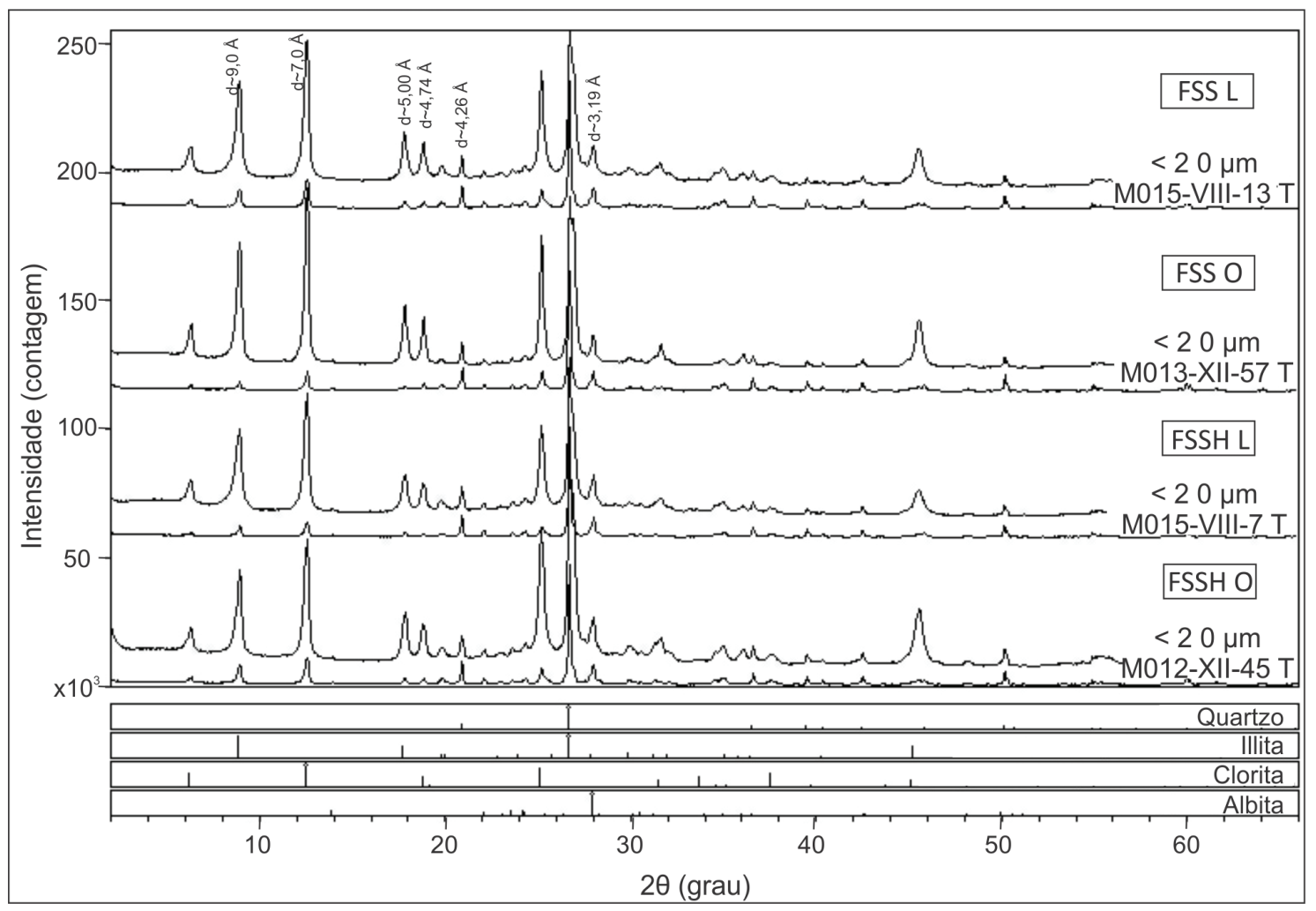

Figura 3. Difratogramas representativos do Grupo I: amostras totais e frações < 2,0 $\mu \mathrm{m}$ da FSSH (M012-XII-45) e FSS (M013XII-57) a oeste (L), em Vila Boa - Bezerra, e a leste (L), na Serra de São Domingos (M015-VIII-7 e M015-VIII-13, respectivamente). Figure 3. Representative diffractograms of Group I: total samples and <2.0 $\mu \mathrm{m}$ fractions of FSSH (M012-XII-45) and FSS (M013XII-57) in the west (O), in Vila Boa - Bezerra, and in east (L), in Serra de São Domingos (M015-VIII-7 and M015-VIII-13, respectively).

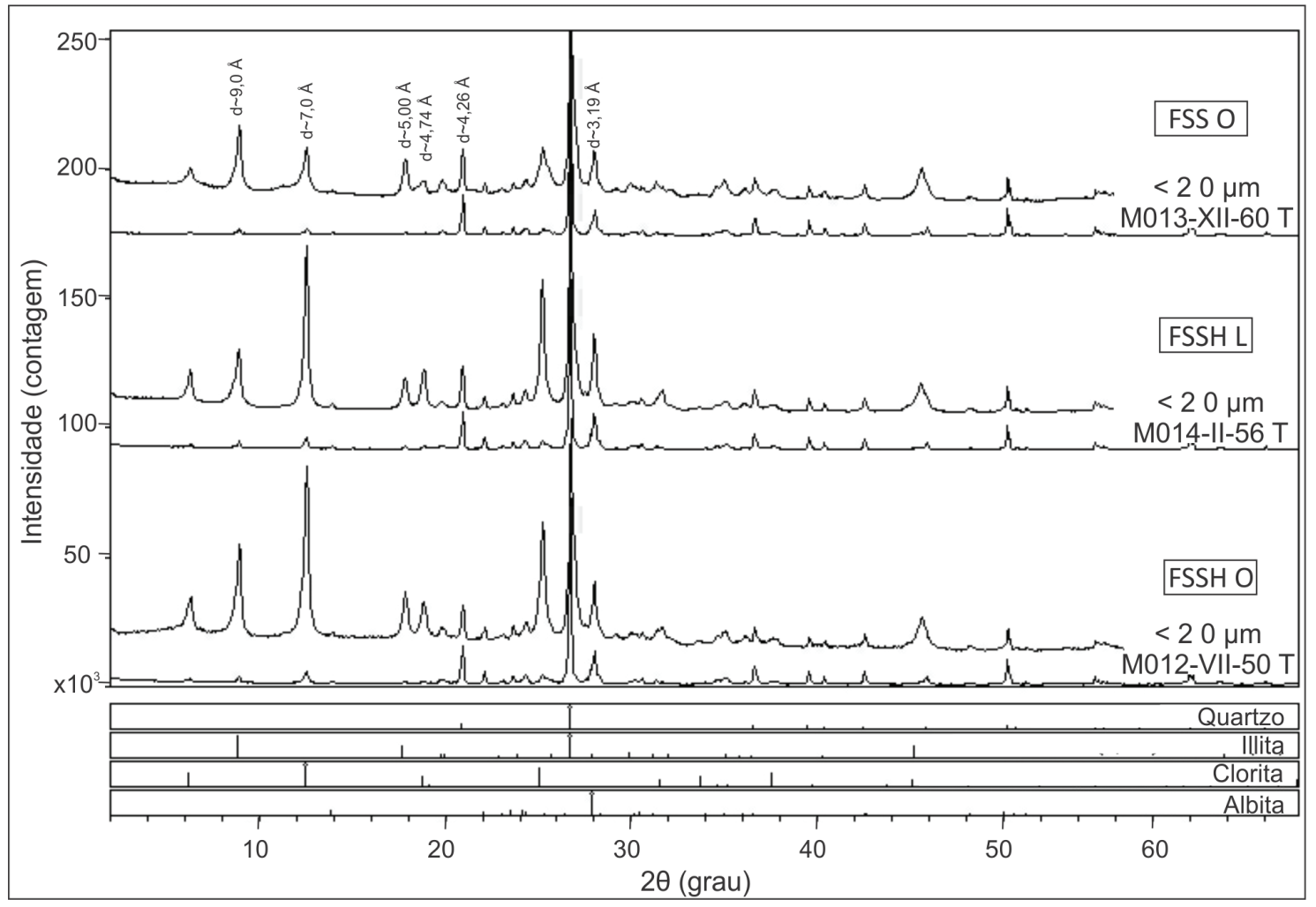

Figura 4. Difratogramas representativas do Grupo II, de amostras totais e frações < 2,0 $\mu$ m, da FSSH (M012-VII-50) e FSS (M013XII-60) a oeste (0), em Vila Boa - Bezerra, e da FSSH (M014-II-56) a leste (L), na Serra de São Domingos.

Figure 4. Representative diffractograms of Group II: total samples and <2.0 $\mu \mathrm{m}$ fractions of FSSH (M012-VII-50) and FSS (M013XII-60) in Vila Boa-Bezerra and FSSH (M014-II-56) in the Serra de São Domingos. 
da na FSSH em Vila Boa - Bezerra e na FSS na Serra de São Domingos. A relação $\mathrm{K}_{2} \mathrm{O} / \mathrm{Na}_{2} \mathrm{O}$ é acima de acima de 1,0, atingindo 2,0 na FSSH em Vila BoaBezerra, da mesma forma que FSS na Serra de São Domingos, tabela 5 (vide material suplementar).

No conjunto mais silicoso (Fig. 5), predominam amostras da FSSH, tendo sido encontrada apenas uma da FSS, na região de Vila Boa - Bezerra. Nesta região estão os valores da FSSH mais altos de $\mathrm{SiO}_{2}$ enquanto que os de $\mathrm{Na}_{2} \mathrm{O}(>3 \%$ ) estão na Serra de São Domingos. Os demais óxidos apresentam valores mais baixos que nas amostras menos silicosas e $\mathrm{Fe}_{2} \mathrm{O}_{3}$ e $\mathrm{MgO}$ têm soma abaixo de 8,0. A razão $\mathrm{K}_{2} \mathrm{O} / \mathrm{Na}_{2} \mathrm{O}$ predominantemente abaixo de 1,0 , tem os menores valores na FSSH na Serra de São Domingos.

\subsection{Características dos minerais}

Os minerais constituintes dos pelitos das formações SSH e SS foram caracterizados quanto aos aspectos texturais por petrografia ótica e MEV, bem como pela química mineral através de análises por sonda eletrônica.

\subsubsection{Aspectos petrográficos}

Grãos de quartzo com extinção reta a levemente ondulante e de feldspatos geralmente são monocristalinos, angulosos a subangulosos (Fig. 6A). Grãos de feldspato potássico, mais comuns nos pelitos da FSSH na região de Vila Boa - Bezerra, são frequentemente bastante alterados, com palhetas de illita ao longo dos planos de clivagem, ou eventualmente mostram macla em xadrez (Fig. 6A). Grãos de plagioclásio às vezes apresentam geminação polissintética (Fig. 6A). Os filossilicatos, identificados por suas características óticas, são muscovita incolor, clorita com pleocroísmo verde amarelado a verde escuro, biotita em geral cloritizada e vermiculita amarelo claro a incolor (Fig. 6B e C). Illita ocorre contornando os grãos de quartzo (Fig. 6D) e também como alteração do feldspato potássico. Lamelas de filossilicatos detríticos normalmente estão orientadas conforme à laminação, frequentemente encurvadas por compactação ou quebradas entre grãos rígidos, feição mais evidente nos pelitos da FSSH na região de Vila Boa - Bezerra (Fig. 7A e B).

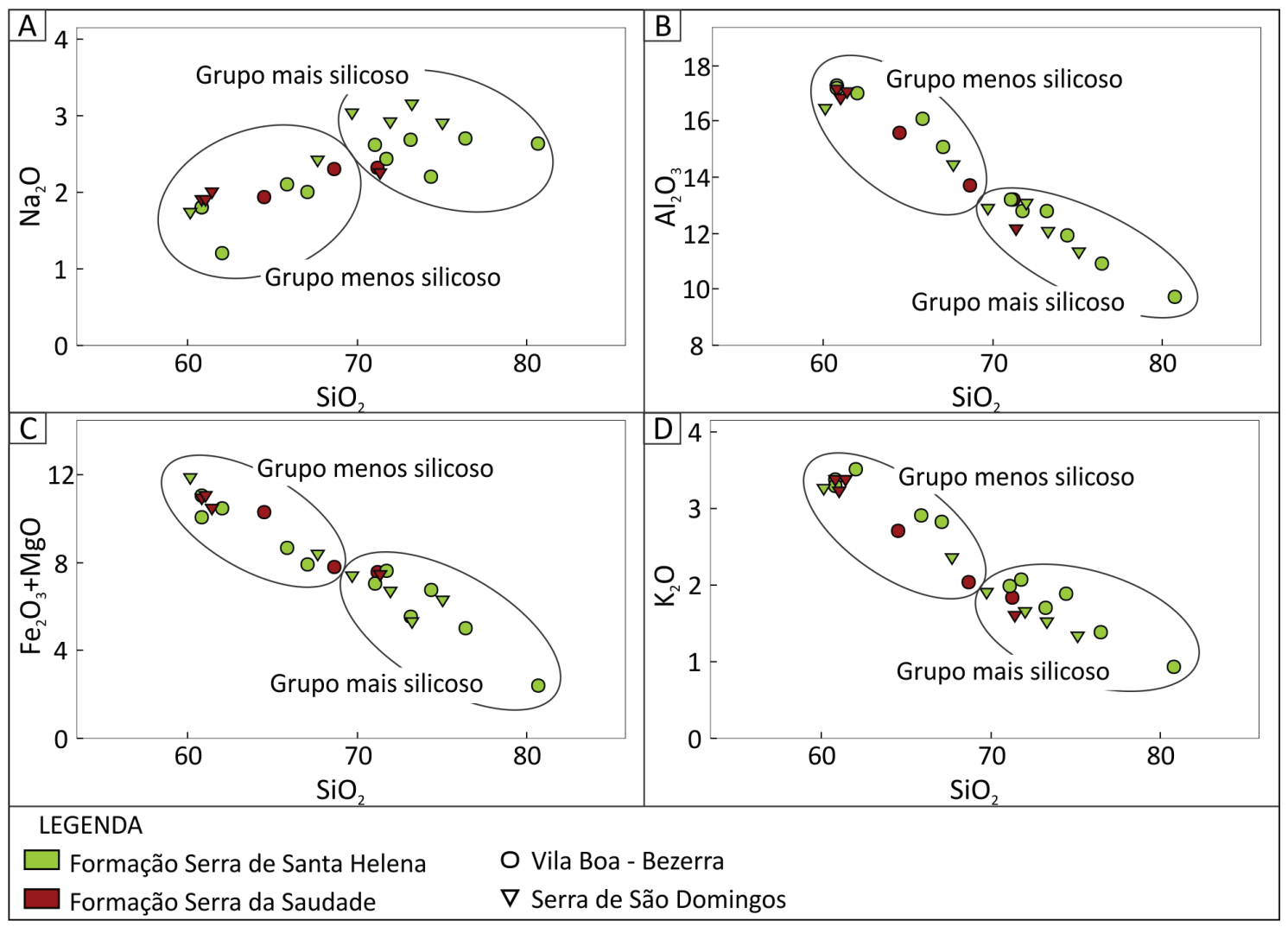

Figura 5. Diagramas de composição química com base em porcentagem de óxidos. A) $\mathrm{Na}_{2} \mathrm{O}$ versus $\mathrm{SiO}_{2}$. B) $\mathrm{Al}_{2} \mathrm{O}_{3}$ versus $\mathrm{SiO}_{2}$. C) $\mathrm{Fe}_{2} \mathrm{O}_{3}+\mathrm{MgO}$ versus $\mathrm{SiO}_{2}$. D) $\mathrm{K}_{2} \mathrm{O}$ versus $\mathrm{SiO}_{2}$.

Figure 5. Chemical composition diagrams based on percentage of oxides. A) $\mathrm{Na}_{2} \mathrm{O}$ versus $\mathrm{SiO}_{2^{\prime}}$ B) $\mathrm{Al}_{2} \mathrm{O}_{3}$ versus $\left.\mathrm{SiO}_{2^{\prime}} \mathrm{C}\right) \mathrm{Fe}_{2} \mathrm{O}_{3}+\mathrm{MgO}$ versus $\mathrm{SiO}_{2}$. D) $\mathrm{K}_{2} \mathrm{O}$ versus $\mathrm{SiO}_{2}$. 


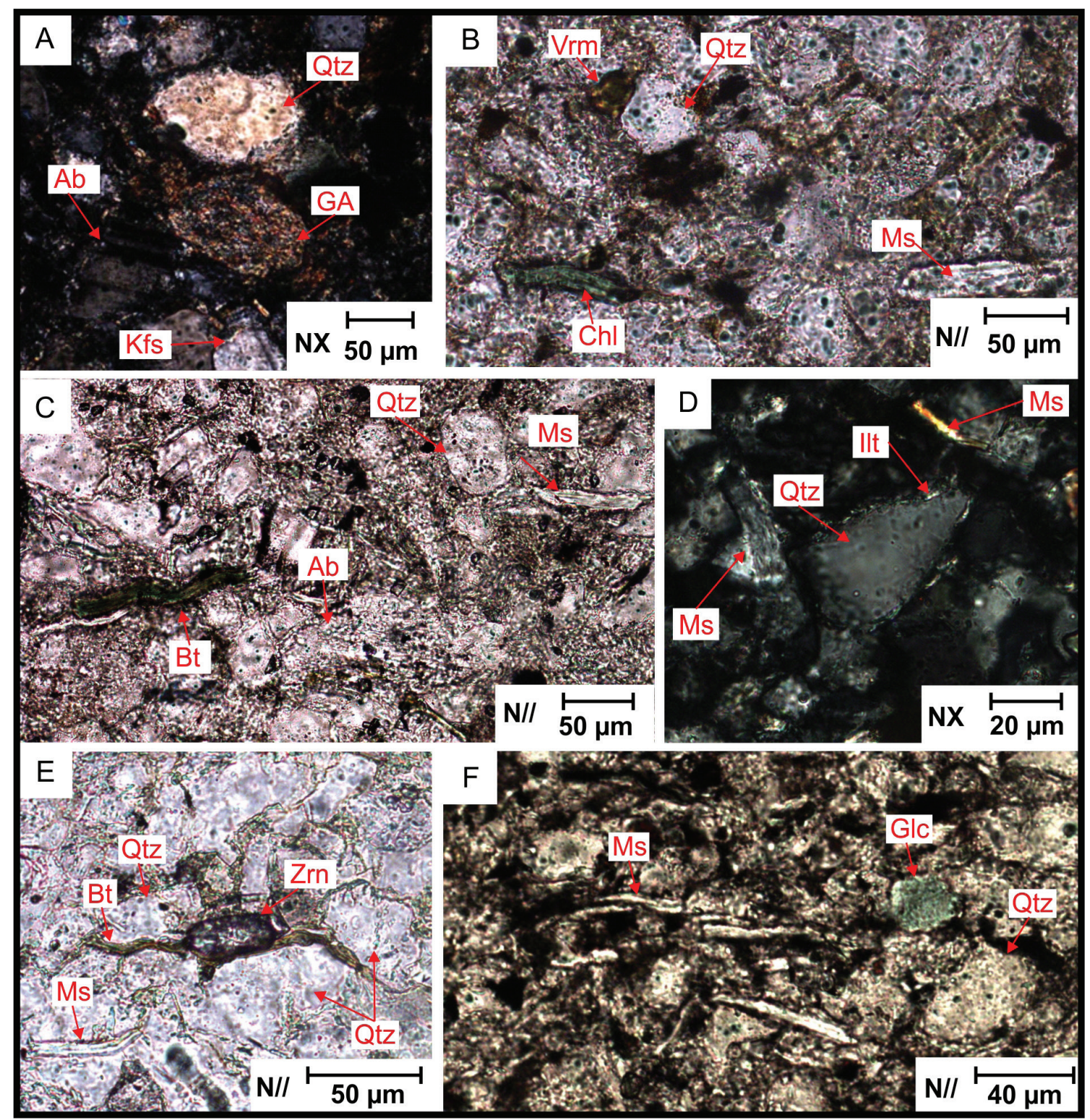

Figura 6. Fotomicrografias de pelitos da FSSH. A) Grãos de quatzo (Qtz) com extinção reta, feldspato potássico (Kfs) com macla em xadrez, de plagioclásio (Ab) com geminação polissintética e grão alterado (GA); B) Lamelas de muscovita (Ms) e clorita (Chl) paralelas ao acamamento, grão anédrico de vermiculita (Vrm); C) Lamelas encurvadas de biotita cloritizada (Bt) e de muscovita (Ms) e de plagioclásio alterado (Ab); D) Palhetas de illita (Ilt) contornando grão de quartzo (Qtz) e lamelas de muscovita (Ms); E) Lamela de biotita cloritizada (Bt) em torno de grão subédrico de zircão (Zrn) e lamela de muscovita (Ms) encurvada; F) Grão detrítico de glauconita (Glc) e lamelas de muscovita (Ms) onduladas.

Figure 6. Photomicrographs of FSSH pelites. A) Quartz grains (Qtz) with straight extinction, potassium feldspar (KfS) with cross-hatched twinning, plagioclase (Ab) with polysynthetic gemination and altered grain (GA); B) Muscovite (Ms) and Chlorite (Chl) flakes parallel to bedding and anhedral vermiculite grain (Vrm); C) Curved flakes of chloritized biotite (Bt) and muscovite (Ms) and altered plagioclase (Ab); D) Illite (Ilt) reeds bypassing quartz grain (Qtz) and muscovite flakes (Ms); E) Chloritized biotite lamella (Bt) around zircon subeuhedral grain ( $\mathrm{Zrn}$ ) and curved muscovite sheet (Ms); F) Glauconite detrital grain (Glc) and curved lamellae of muscovite (Ms). 


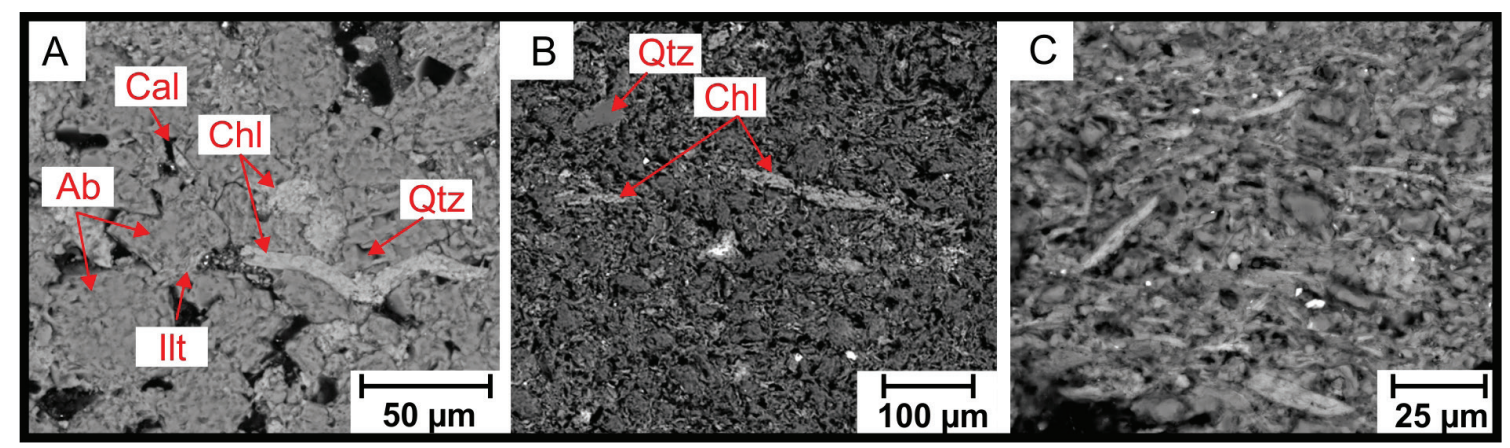

Figura 7. Imagens retroespalhadas por MEV. A) Lamela de clorita (Chl) encurvada ao redor de grão de quartzo (Qtz), palheta de illita (Ilt) na borda de grão de plagioclásio (Ab) e cristal de calcita (Cal), FSSH; B) Lamela de clorita (Chl) ondulada e grão de quartzo (Qtz) em meio a lama pelítica, FSS; C) Lamelas de filossilicatos sem direção preferencial, FSSH.

Figure 7. Backscattered images by MEV. A) Chlorite lamella (Chl) curved around quartz grain (Qtz), illite reeds (Ilt) on the border of plagioclase grain (Ab) and calcite crystal (Cal), FSSH; B) Chlorite (Chl) lamella curved and quartz grain (Qtz) in the middle of pelitic mud, FSS; C) Phyllosilicates lamellae without preferential direction, FSSH.

Palhetas mais finas comumente são observadas sem direção preferencial (Fig. 7C). Nos pelitos da FSSH são identificados ainda grãos detríticos de zircão subédrico (Fig. 6E) e de glauconita (Fig. 6F) e grãos constituídos por lamelas finas de filossilicatos, que podem ser alteração de feldspato ou de fragmento lítico (Fig. 6A).

\subsubsection{Química mineral dos filossilicatos}

Detalhando por sonda eletrônica a composição química dos filossilicatos, entre as análises válidas, raros resultados de micas dioctaédricas se aproximam da fórmula ideal da muscovita (tabelas 6 e 7 - vide material suplementar), enquanto espécies trioctaédricas têm composições entre biotita e clorita (tabelas 8, 9, 10 e 11 - vide material suplementar; Fig. 8).

A composição ideal da muscovita (Deer et al. 1992) tem Si igual ou levemente maior que 6,0, soma dos octaedros próxima de 4,0 e álcalis em torno de 2,0. Al total é de aproximadamente 6,0 (2,0 no tetraedro e 4,0 no octaedro), enquanto $\mathrm{Fe}+\mathrm{Mg}$ tende a zero. As illitas tem silício maior que 6,0 até cerca de 7,0, a soma dos octaedros é inferior a 4,0 e dos álcalis é inferior a 2,0, cujos valores variam de 1,5 a 1,8. Al se situa entre 5,0 e 5,5, e o conteúdo em Fe+Mg é variável, abaixo de 1,0. De acordo com estas características, os filossilicatos analisados foram discriminados como "próximos à muscovita" (tabela 6 - vide material suplementar), correspondentes ao primeiro caso e "illita", associados ao último (tabela 7 - vide material suplementar).
Em ambos são registrados valores dos octaedros abaixo de 4,0, mas a maioria tem valores mais altos, que podem estar relacionados a inclusões de cristálitos de óxidos de Fe nos filossilicatos, ou interestratificação com minerais trioctaédricos e/ou misturas com clorita.

Nas análises que mostram composição "próxima à muscovita" (tabela 6 - vide material suplementar), os valores de Si variam entre 6,10 e 6,90, os octaedros têm soma entre 3,83 a 4,11 (Fig. 9A), correspondente a 2,84 até 3,62 de $\mathrm{Al}$ e 0,37 a 1,07 de $\mathrm{Fe}+\mathrm{Mg}$ (Fig. 9B), enquanto a soma de álcalis está entre 1,55 e 2,05 (Fig. 9C) na FSSH em Vila Boa - Bezerra. A maioria destas análises foram obtidas sobre lâminas da FSSH na região de Vila Boa - Bezerra, já que as amostras provenientes da Serra de São Domingos e da FSS são de granulometria mais fina, contendo raras lamelas de micas.

Análises atribuídas a "illita" são aquelas com valores de Si próximos ou acima de 7,0, os octaedros com a soma em torno de 4,0, comumente apresentando vacância, enquanto o total de álcalis é inferior a 1,6. De modo geral (tabela 7 - vide material suplementar), as análises da região de Vila Boa - Bezerra mostram maior dispersão do conteúdo de Si em ambas as formações: de 6,30 a 7,82 na FSSH e de 7,48 a 7,84 na FSS. Na Serra de São Domingos os valores de Si variam de 7,35 a 7,85 na FSSH e de 7,45 a 7,58 na FSS. Assim como o conteúdo de $\mathrm{Si}$, a soma dos octaedros (Fig. 8A) também é mais dispersa em Vila Boa - Bezerra com valores mais elevados de $\mathrm{Fe}+\mathrm{Mg}$ se comparadas às análises "próxima à muscovita" (Fig. 9B). Na FSSH 


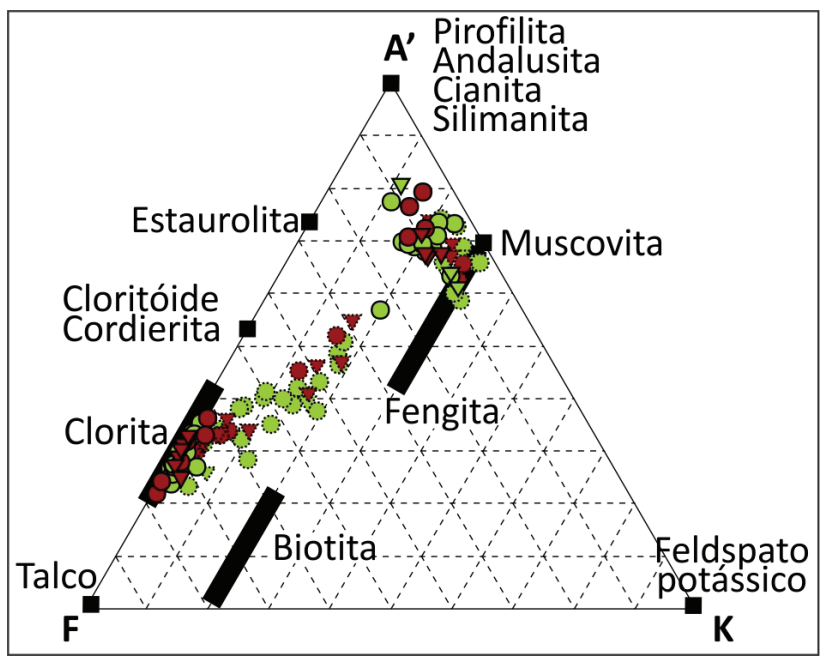

Figura 8. Composição dos filossilicatos em \% de óxidos: $A^{\prime}$ $=\left(\mathrm{Al}_{2} \mathrm{O}_{3}+\mathrm{Fe}_{2} \mathrm{O}_{3}\right)-\left(\mathrm{K}_{2} \mathrm{O}+\mathrm{CaO}+\mathrm{Na}_{2} \mathrm{O}\right), \mathrm{K}=\mathrm{K}_{2} \mathrm{O}$ e $\mathrm{F}=\mathrm{FeO}+\mathrm{MgO}$ mostrando dois campos: um próximo à muscovita e outro entre clorita e biotita, ambos com tendência a baixo $\mathrm{K}_{2} \mathrm{O}$ e alto $\mathrm{Al}_{2} \mathrm{O}_{3}+\mathrm{Fe}_{2} \mathrm{O}_{3}$ para as micas. Os símbolos estão descritos na fig. 5 .

Figure 8. Phyllossilicates composition in \% of oxides: $\mathrm{A}^{\prime}=\mathrm{Al}_{2} \mathrm{O}_{3}+-$ $\left.\mathrm{Fe}_{2} \mathrm{O}_{3}\right)-\left(\mathrm{K}_{2} \mathrm{O}+\mathrm{CaO}+\mathrm{Na}_{2} \mathrm{O}\right), \mathrm{K}=\mathrm{K}_{2} \mathrm{O}$ e $\mathrm{F}=\mathrm{FeO}+\mathrm{MgO}$, showing two fields: one near the muscovite and the other between chlorite and biotite, both with $\mathrm{K}_{2} \mathrm{O}$ depleted tendency and high $\mathrm{Al}_{2} \mathrm{O}_{3}+-$ $\mathrm{Fe}_{2} \mathrm{O}_{3}$ for the micas. The symbols are in fig. 5 .

nessa região, varia de 3,61 a 4,38 e na FSS de 3,55 a 3,93 enquanto que na Serra de São Domingos varia de 3,07 a 4,11 e 3,84 a 3,96, na FSSH e na FSS, respectivamente. Ao contrário desses parâmetros, a soma de álcalis (Fig. 9C) na FSSH varia de 1,16 a 1,57 em Vila Boa - Bezerra e de 0,85 a 1,51 na Serra de São Domingos e, na FSS, de 1,14 a 1,69 e de 1,14 a 1,43 nessa ordem, sendo então os valores na Serra de São Domingos mais dispersos.

A composição ideal da biotita (Deer et al., 1992) tem Si entre 5,0 e 6,0, soma dos octaedros entre 5,6 e 5,9 e álcalis em torno de 2,0 e as cloritas têm silício entre 5,0 e 7,0, soma dos octaedros próxima a 12 e dos álcalis próximo a 0 .

Os filossilicatos trioctaédricos da FSSH, tabela 8 (vide material suplementar), têm Si entre 5,14 e 7,44, a soma dos octaedros entre 4,55 e 6,85 e de álcalis entre 0,16 e 1,53 (Fig. 9A), sendo bastante dispersos ainda que a maioria das análises seja em Vila Boa - Bezerra. Nessa região, as micas da FSS, tabela 9 (vide material suplementar), têm esses valores ligeiramente menores e menos dispersos: $\mathrm{Si}$ varia entre 5,18 e 6,18, soma dos octaedros entre 4,92 e 6,45 e de álcalis entre $0,4231,06$. Por outro lado, na Serra de São Domingos a composição das cloritas também é variada: valores de Si variam de
4,81 a 7,13, soma dos octaedros de 4,43 a 6,80 e álcalis de 0,62 a 1,40. Raras análises se aproximam então da composição da biotita, predominando filossilicatos com deficiência nesses valores.

As cloritas da FSSH, tabela 10 (vide material suplementar), assim com os filossilicatos trioctaédricos, predominam em Vila Boa - Bezerra e têm valores de $\mathrm{Si}$ de 5,60 a 6,66, soma dos octaedros de 11,00 a 11,85 e soma dos álcalis de 0,08 a 0,75. $\mathrm{Na}$ FSS, tabela 11 (vide material suplementar), esses valores são menos dispersos, especialmente na Serra de São Domingos, onde Si varia de 5,80 a 6,15, soma dos octaedros de 11,21 a 11,68 e soma dos álcalis de 0,16 a 0,56. Em Vila Boa - Bezerra, Si varia de 5,46 a 6,07 , soma dos octaedros de 11,03 a 11,84 e álcalis de 0,14 a 0,55.

Utilizando-se o diagrama $\mathrm{MR}^{3+}-2 \mathrm{R}^{3+}-3 \mathrm{R}^{2+}$ para representar as espécies de filossilicatos di e tri-octaédricos, em que $\mathrm{MR}^{3+}=\mathrm{Na}^{+}+\mathrm{K}^{+}+2 \mathrm{Ca}^{+}, 2 \mathrm{R}^{3+}$ $=\mathrm{Al}^{3+}+\mathrm{Fe}^{3+}$, e $3 \mathrm{R}^{2+}=\mathrm{Fe}^{2+}+\mathrm{Mg}^{2+}+\mathrm{Mn}^{2+}$, observa-se a distribuição das análises em dois campos distintos: um deles na área da illita (Fig. 10) e outro dos filossilicatos trioctaédricos que se aproximam do campo da clorita mas com excesso de álcalis.

De acordo com as análises, as micas e cloritas da FSSH na região de Vila Boa - Bezerra têm composições mais variadas do que na FSS. Além disso, de modo geral nas duas unidades, a perda de álcalis nas espécies tri-octaédricas é maior do que nas micas dioctaédricas.

\section{Discussão}

Os argilominerais, depositados predominantemente por decantação em ambiente aquoso, trazem informações sobre sua proveniência, registradas na composição mineral e química. Visto que eventos pós-deposicionais, condicionados principalmente pela temperatura, modificam a composição mineral, esta torna-se um indicador da intensidade da diagênese, principalmente pela paragênese e pela largura a meia altura de reflexões da illita e da clorita. Por outro lado, a baixa permeabilidade dos sedimentos pelíticos mantêm um sistema relativamente fechado, em que as transformações minerais são isoquímicas, guardando a composição química dos sedimentos. Assim, os resultados obtidos neste trabalho são utilizados 


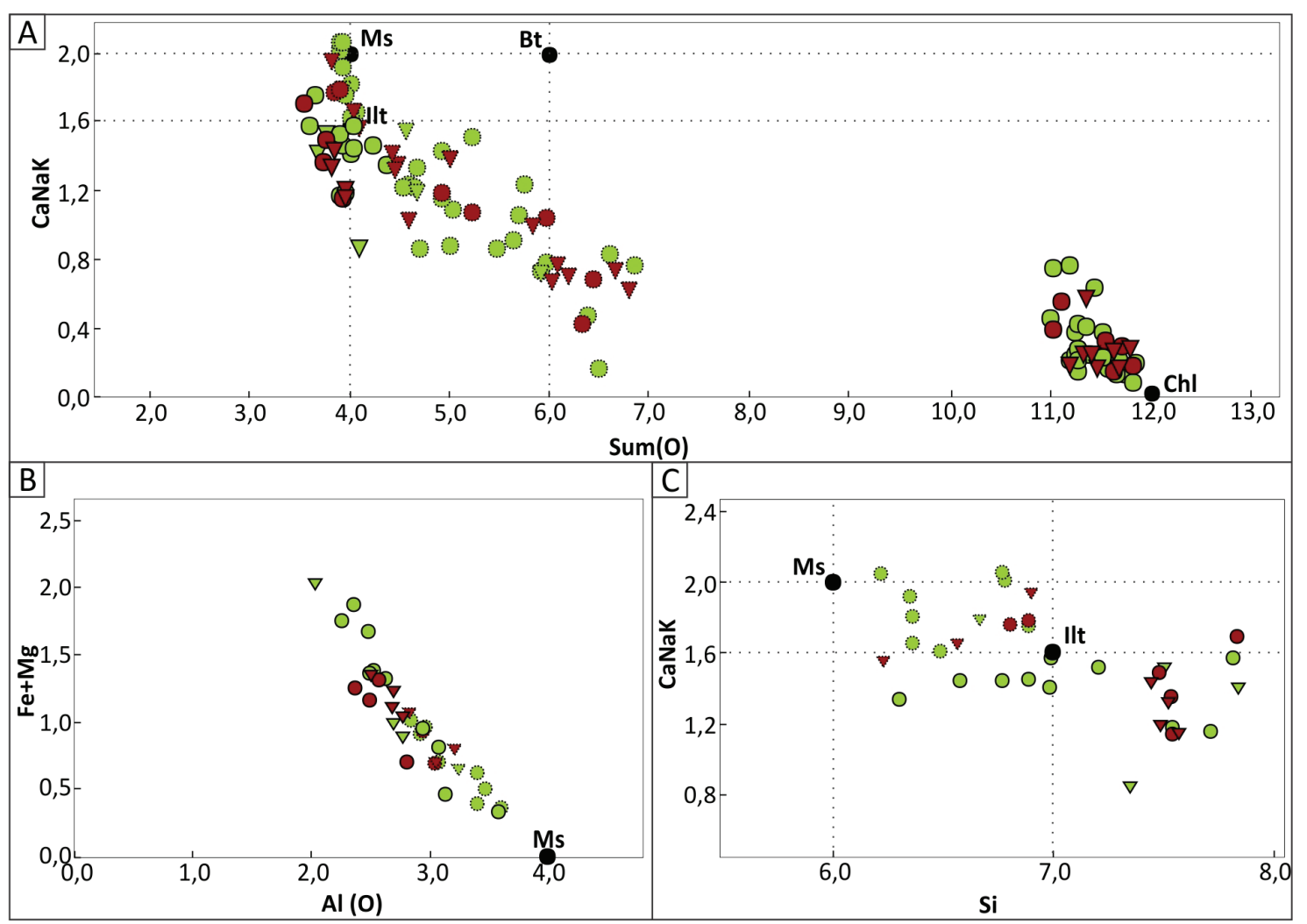

Figura 9. Composição química dos filossilicatos por sonda eletrônica. A) Álcalis versus soma dos octaedros; $\mathrm{B}$ ) Fe+Mg versus Al (0) de micas dioctaédricas; C) Álcalis versus Si nas micas dioctaédricas. Notar composição de micas dioctaédricas compatíveis com muscovita e illita (borda pontilhada) e outras com micas transformadas (borda contínua), assim como os filossilicatos têm composições intermediárias entre biotita e clorita (borda pontilhada) e outros compatíveis com a clorita (borda contínua). Os símbolos estão descritos na fig. 5.

Figure 9. Chemical composition of phyllosilicates by electronic probe A) Alkalis versus sum of octahedra; B) Fe $+\mathrm{Mg}$ versus Al (O) of dioctahedral micas; $C$ ) Alkalis versus Si in dioctahedral micas. Note the dioctahedral micas composition compatible with muscovite and illite (dotted border) and others with transformed micas (continuous border), as well as phyllosilicates have intermediate compositions between biotite and chlorite (dotted border) and others compatible with chlorite (continuous edge). The symbols are in fig. 5.

para interpretações das condições deposicionais, enquanto outros trabalhos (Guimarães, 1997; Campos et al., 2015; Sampaio, 2016) indicam condições diagenéticas.

\subsection{Indicadores petrográficos e mineralógicos de proveniência e deposição}

As estruturas sedimentares indicam deposição de silte e argila, por decantação, mas especialmente na FSSH ocorrem arenitos com estruturas de fluxo direcional, o qual é menos comum nos pelitos da FSS, em razão da predominância da granulometria mais fina.

Na região norte do $\mathrm{DF}$, arenitos da FSSH são descritos como subquartzosos, constituídos por feldspatos, fragmentos líticos portadores de biotita, clorita pseudomorfa sobre anfibólio, tendo a matriz (ou pseudomatriz) formada por argilominerais (illita e clorita), quartzo e minerais opacos
(Campos, 2012). Apresentando composição mineral semelhante, os siltitos da FSSH correspondem à fase de granulometria fina depositada em condições de menor energia.

A composição dos siltitos, particularmente pela presença de minerais quimicamente instáveis, como plagioclásio e biotita, indica baixa taxa de alteração na área-fonte, enquanto a clorita, em geral associada à biotita, é interpretada como alteração desta durante a diagênese. Esta interpretação é sustentada também pela química mineral que mostra composição dos filossilicatos trioctaédricos próxima à da biotita, mas com deficiência de álcalis e da soma do octaedro. Por outro lado, as análises atribuídas à clorita, que mostram conteúdo relativamente alto de álcalis, provavelmente são remanescentes das biotitas, enquanto outras com menor percentagem de álcalis teriam se originado de outros minerais máficos. Outra alteração durante a diagênese é de muscovita para illita, sus- 


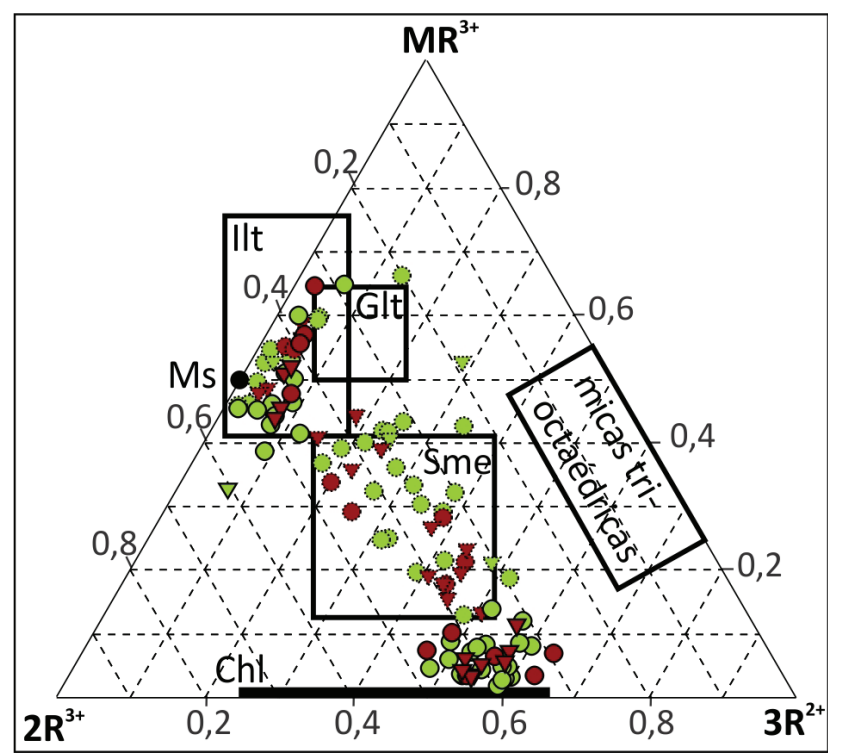

Figura 10. Diagrama $\mathrm{MR}^{3+}-2 \mathrm{R}^{3+}-3 \mathrm{R}^{2+}$, cujos sítios correspondem

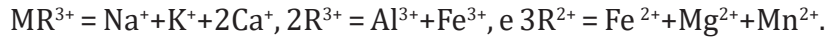
Os símbolos estão descritos na fig. 5 .

Figure 10. $M R^{3+}-2 R^{3+}-3 R^{2+}$ diagram, whose sites correspond $\mathrm{MR}^{3+}=\mathrm{Na}^{+}+\mathrm{K}^{+}+2 \mathrm{Ca}^{+}, 2 \mathrm{R}^{3+}=\mathrm{Al}^{3+}+\mathrm{Fe}^{3+}$, e $3 \mathrm{R}^{2+}=\mathrm{Fe}^{2+}+\mathrm{Mg}^{2+}+\mathrm{Mn}^{2+}$. The symbols are in fig. 5 .

tentada pela petrografia e pela química mineral, pois os valores das micas dioctaédricas se aproximam da muscovita mas são deficientes em álcalis com valores mais altos de $\mathrm{Si}$.

Minerais instáveis preservados nos siltitos indicam também a proximidade entre o sítio deposicional e a área-fonte sujeita a erosão, sendo os sedimentos transportados e depositados rapidamente.

A composição mineral - quartzo, mica dioctaédrica e plagioclásio - de ambas as formações indica a existência na área-fonte de rocha sílico-aluminosa, enquanto a percentagem relativamente alta de biotita e clorita indique também uma contribuição de rocha portadora de minerais ferromagnesianos. Rochas sílico-aluminosas constituem o embasamento granito-gnáissico, mas neste caso as taxas de feldspatos potássicos nos siltitos seriam mais altas, como acontece no Grupo Paranoá (Guimarães, 1997). Uma possível fonte, particularmente das micas dioctaédricas podem ser consideradas as rochas do Grupo Canastra, constituído de xistos e quartzitos (Freitas-Silva \& Dardenne, 1994). Na FSSH, a presença de grãos dispersos de glauconita e zircão subédrico indica ainda reciclagem sedimentar, provavelmente a partir de rochas do Grupo Paranoá, subjacente, portador de corpos de arenitos glauconíticos (Gui- marães \& Dardenne, 2005; Costa Neto, 2006). A fonte de plagioclásio e biotita (ou outro mineral máfico precursor de clorita) tem sido atribuída à erosão de rochas expostas pela Orogênese Brasiliana (Alkmin et al., 1993; Guimarães, 1997), seja o Arco Magmático de Goiás (Pimentel, 2001), ou relacionadas aos Complexos Máfico-Ultramáfico e sequências vulcano-sedimentares.

Considerando a composição química das rochas, os pelitos da FSSH são, de forma geral, mais ricos em $\mathrm{SiO}_{2}$ e em $\mathrm{Na}_{2} \mathrm{O}$ do que os da FSS, que por sua vez são mais ricos em $\mathrm{Al}_{2} \mathrm{O}_{3}$ e $\mathrm{K}_{2} \mathrm{O}$. Embora a classificação de Pettijohn et al. (1987) seja originalmente para arenitos, ao plotar a composição química dos pelitos no diagrama, nota-se facilmente essa diferença entre as formações, que reflete maior compatibilidade dos pelitos da FSSH com a composição de litarenitos, enquanto as rochas da FSS, com as grauvacas, o que está de acordo com a descrição petrográfica, que aponta, para esta formação, maior percentagem de material fino não identificado (MFNI), bem como de filossilicatos por DRX (Fig. 11).

\subsection{Indicadores geoquímicos de proveniência}

Para a interpretação da proveniência a partir de indicadores geoquímicos, ressalta-se que os siltitos analisados são isentos de intemperismo, com base tanto na coloração e, principalmente, na ausência das reflexões em difratogramas de raios X da esmectita ou interestratificados que indiquem o início do intemperismo destas rochas. Dessa forma, a composição química das rochas sedimentares siliciclásticas reflete a distribuição granulométrica, em que o conteúdo de Si e, particularmente $\mathrm{Al}$, indica a proporção de argilominerais, predominantes na fração mais fina, enquanto os silicatos não argilosos são os principais constituintes dos termos mais grossos.

A razão entre os diversos óxidos $-\mathrm{Fe}_{2} \mathrm{O}_{3}, \mathrm{~K}_{2} \mathrm{O}$,

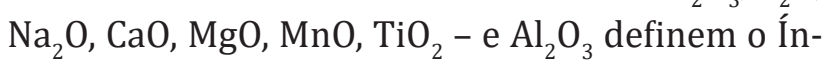
dice de Variação Composicional - IVC - (ICV: Index of Compositional Variability), indicativo da maturidade das rochas pelíticas, que por sua vez podem ser associadas ao contexto tectônico de deposição (Cox et al., 1995).

Considerando o IVC (Fig. 12), as amostras 


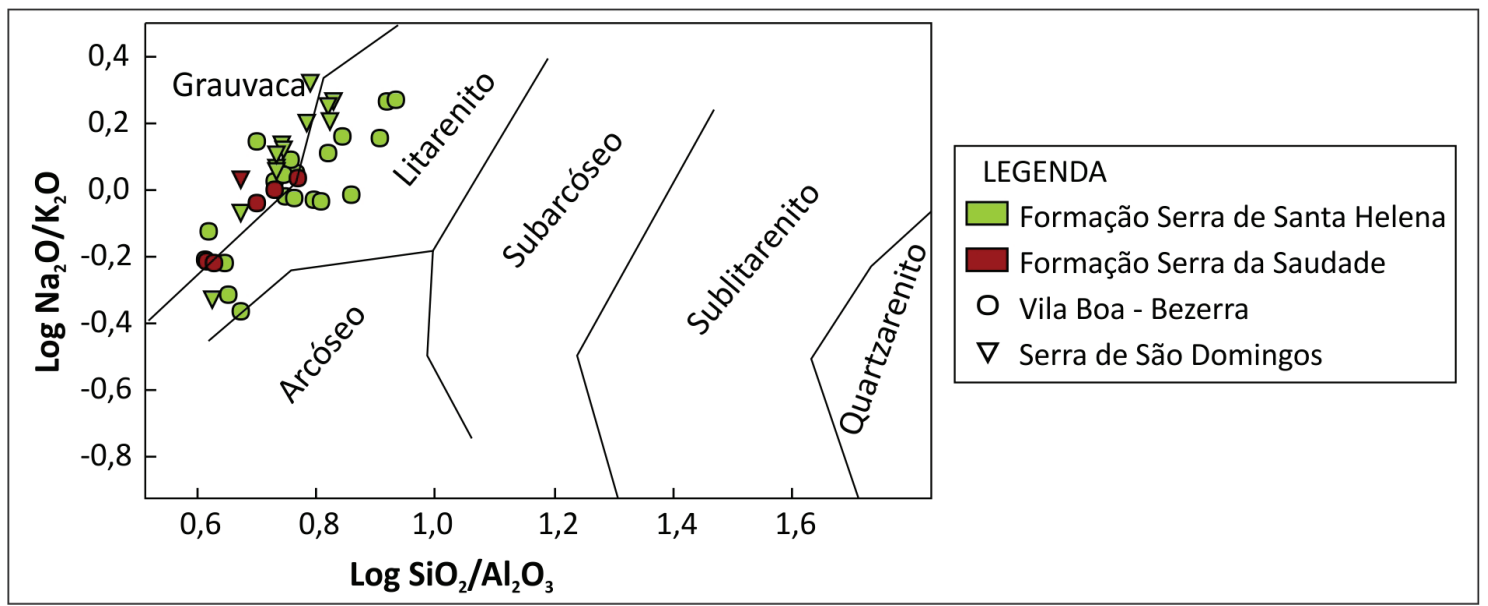

Figura 11. Diagrama de classificação petroquímica de Pettijohn et al. (1987).

Figure 11. Petrochemical classification diagram of Pettijohn et al. (1987).

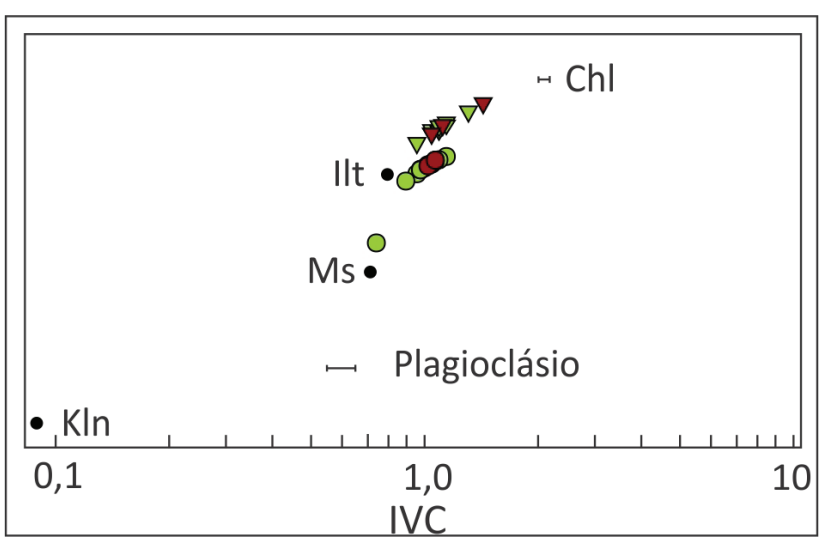

Figura 12. Índice de Varibilidade Composicional (IVC) mostrando valores mais dispersos na FSSH em Vila Boa - Bezerra, e na FSS, valores mais homogêneos. Os símbolos estão descritos na Fig. 11.

Figure 12. Index of Compositional Variability (ICV) showing more dispersed values in the FSSH in Vila Boa - Bezerra and, in the FSS, more homogeneous values. The symbols are in Fig. 11.

mais silicosas da FSSH ocorrem na porção oeste com ampla dispersão, tendo valores entre $0,74 \mathrm{e}$ 1,15 , enquanto na região leste, estes valores são levemente mais homogêneos $(0,96$ e 1,31). As amostras menos silicosas são mais homogêneas tanto a oeste $(0,95$ a 1,05$)$, como a leste $(1,04$ a 1,14$)$. De acordo com esses valores, as rochas da FSSH são formadas por pelitos imaturos, com alguma contribuição de sedimentos mais maturos na porção oeste e pode-se inferir a variação no aporte de sedimentos mais grossos (siltitos grossos) na porção oeste, com tendência à homogeneização a leste e nos termos mais argilosos.
Os pelitos da FSS são mais homogêneos quanto ao IVC, com valores entre 1,03 e 1,08 a oeste e 1,05 e 1,12 a leste, sendo portanto, imaturos e, aparentemente, provenientes de área fonte persistente.

As razões $\mathrm{K}_{2} \mathrm{O} / \mathrm{Al}_{2} \mathrm{O}_{3}$ e $\mathrm{MgO} / \mathrm{Al}_{2} \mathrm{O}_{3}$ dos pelitos são dependentes particularmente das proporções de filossilicatos, respectivamente, di ou trioctaédricos, sendo mais elevadas portanto nas porções menos silicosas, enquanto $\mathrm{Na}_{2} \mathrm{O} / \mathrm{Al}_{2} \mathrm{O}_{3}$ depende da proporção de plagioclásio e é maior nas porções mais silicosas.

Nos pelitos menos silicosos da FSSH as razões $\mathrm{K}_{2} \mathrm{O} / \mathrm{Al}_{2} \mathrm{O}_{3}, \mathrm{MgO} / \mathrm{Al}_{2} \mathrm{O}_{3}$ e $\mathrm{Na}_{2} \mathrm{O} / \mathrm{Al}_{2} \mathrm{O}_{3}$ variam respectivamente de 0,20 a 0,23, 0,14 a 0,19 e 0,10 a 0,17 , tanto a oeste quanto a leste, tabela 12 (vide material suplementar). Por outro lado, nos pelitos mais silicosos $\mathrm{K}_{2} \mathrm{O} / \mathrm{Al}_{2} \mathrm{O}_{3}$ e $\mathrm{MgO} / \mathrm{Al}_{2} \mathrm{O}_{3}$ tendem a ser mais homogêneos a leste, com valores de 0,16 a 0,19 e 0,13 a 0,19 enquanto a oeste esses valores são de 0,15 a 0,22 e de 0,05 a 0,16 (Fig. 13A). Nessa região, a razão $\mathrm{Na}_{2} \mathrm{O} / \mathrm{Al}_{2} \mathrm{O}_{3}$ é mais heterogênea, com valores de 0,13 a 0,27 enquanto que a leste varia de 0,20 a 0,26 (Fig. 13B). Essas razões mais dispersas nos siltitos mais grossos registram variações da rocha fonte, não registradas nos pelitos mais finos (menos silicosos), e atribuídas ao selecionamento granulométrico.

$\mathrm{Na}$ FSS, as razões $\mathrm{K}_{2} \mathrm{O} / \mathrm{Al}_{2} \mathrm{O}_{3}, \mathrm{MgO} / \mathrm{Al}_{2} \mathrm{O}_{3}$ e $\mathrm{Na}_{2} \mathrm{O} / \mathrm{Al}_{2} \mathrm{O}_{3}$ têm valores respectivamente de 0,17 a $0,21,0,14$ a 0,18 e 0,12 a 0,18 a oeste enquanto a leste correspondem a 0,22 e $0,23,0,18$ a 0,20 e 0,11 a 0,12 (Fig. 13A e B) e tabela 12 (vide material suplemen- 
tar). Portanto, pode-se inferir maior variação nas rochas fontes a oeste do que a leste.

Comparando a unidade inferior (FSSH) com a unidade superior (FSS), verifica-se que as razões $\mathrm{K}_{2} \mathrm{O} / \mathrm{Al}_{2} \mathrm{O}_{3}$ e $\mathrm{MgO} / \mathrm{Al}_{2} \mathrm{O}_{3}$ tendem a valores maiores no topo, confirmando maior contribuição de sedimentos ferromagnesianos.
De forma geral, a FSSH é então mais heterogênea refletindo maior variação de rochas-fonte e seleção granulométrica, enquanto a FSS tende a ser mais homogênea, como observado preliminarmente por Campos \& Guimarães (2017; Fig. 14A e B).
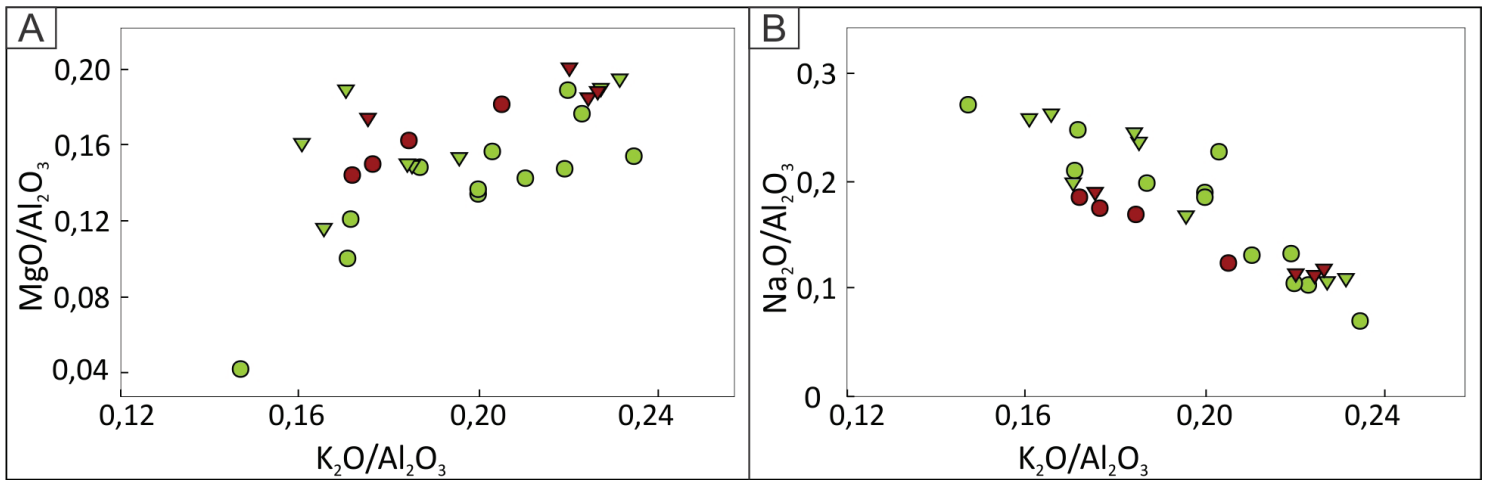

Figura 13. Relação entre razões normalizadas com $\mathrm{Al}_{2} \mathrm{O}_{3}$. A) $\mathrm{MgO} / \mathrm{Al}_{2} \mathrm{O}_{3}$ versus $\mathrm{K}_{2} \mathrm{O} / \mathrm{Al}_{2} \mathrm{O}_{3}$ mostrando tendência de valores mais altos de $\mathrm{MgO}$ dos pelitos da FSS do que da FSSH; B) $\mathrm{Na}_{2} \mathrm{O} / \mathrm{Al}_{2} \mathrm{O}_{3}$ versus $\mathrm{K}_{2} \mathrm{O} / \mathrm{Al}_{2} \mathrm{O}_{3}$ mostrando tendência de valores mais altos de $\mathrm{Na}_{2} \mathrm{O}$ da FSSH do que na FSS. Os símbolos estão descritos na Fig. 11.

Figure 13. Relation between normalized ratios with $\mathrm{Al}_{2} \mathrm{O}_{3}$. A) $\mathrm{MgO} / \mathrm{Al}_{2} \mathrm{O}_{3}$ versus $\mathrm{K}_{2} \mathrm{O} / \mathrm{Al}_{2} \mathrm{O}_{3}$ showing tendency of higher $\mathrm{MgO}$ values of the FSS pelites than of the FSSH; $\mathrm{B}) \mathrm{Na}_{2} \mathrm{O} / \mathrm{Al}_{2} \mathrm{O}_{3}$ versus $\mathrm{K}_{2} \mathrm{O} / \mathrm{Al}_{2} \mathrm{O}_{3}$ showing a tendency for higher values of Na2O in the FSSH than in the FSS. The symbols are in Fig. 11.

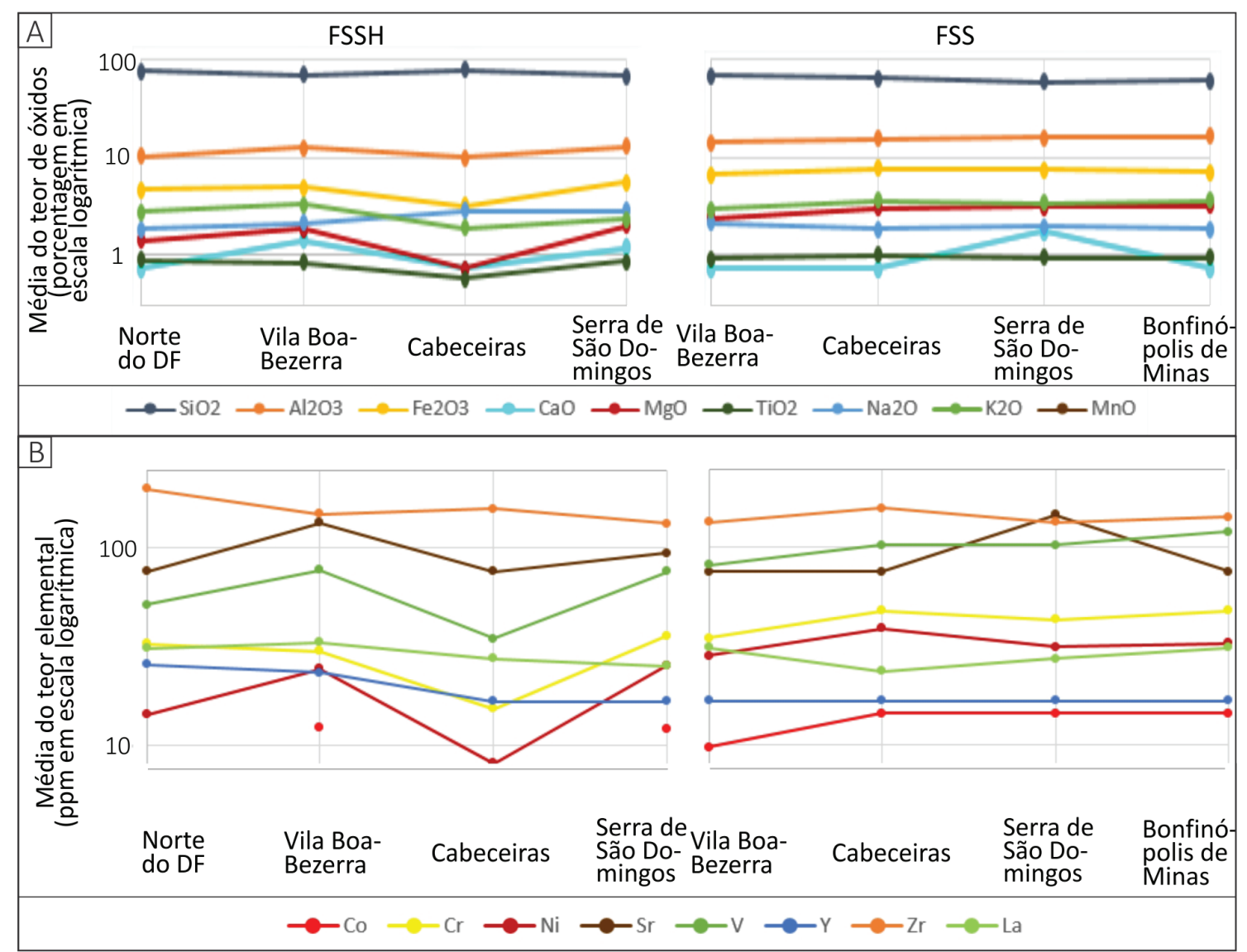

Figura 14. Composição geoquímica dos pelitos das formações FSSH e FSS. A) Média das porcentagens de óxidos agrupados conforme classe modal em cada localidade (Campos \& Guimarães, 2017); B) Média dos teores elementais agrupados conforme classe modal em cada localidade (Campos \& Guimarães, 2017).

Figure 14. Geochemical composition of the pelites of the FSSH and FSS formations. A) Mean of percentages of oxides grouped according to modal class in each locality (Campos \& Guimarães, 2017); B) Mean of the elemental contents grouped according to modal class in each locality (Campos \& Guimarães, 2017). 


\section{Conclusões}

Utilizando dados de petrografia, difratometria de raios $\mathrm{X}$, química mineral e química de rocha total, observa-se que na FSSH, região de Vila Boa - Bezerra (oeste), há maior variação de estruturas sedimentares, composição mineral e composição química do que na região da Serra de São Domingos (leste). Na FSS, os pelitos tendem a maior homogeneidade tanto em Vila Boa - Bezerra (oeste) como na região da Serra de São Domingos (leste).

Além disso, a FSS contém maior contribuição de minerais ferromagnesianos, representados por clorita e biotita e em ambas as formações é confirmada a seleção granulométrica, em que os pelitos mais finos são constituídos essencialmente por filossilicatos enquanto os mais grossos contêm maior porcentagem de silicatos não argilosos, principalmente albita.

O Índice de Variação Composicional (IVC), indica sedimentos imaturos, com IVC em torno de 1,0 , em ambas as unidades tanto a oeste quanto a leste, que tendem a ser encontrados em áreas tectonicamente ativas provavelmente associadas à evoluçã0o da Faixa de Dobramentos Brasília. Entretanto, a FSSH na região de Vila Boa - Bezerra (oeste) mostra também pelitos mais maturos, com contribuição de sedimentos reciclados provenientes do Grupo Paranoá (glauconita e zircão), sendo que valores distintos de IVC nas duas unidades indicam variação da rocha fonte.

Agradecimentos. Esse artigo é parte constituinte de tese de doutoramento da primeira autora. Os autores agradecem ao Centro Regional para o Desenvolvimento Tecnológico e Inovação (CRTI/ UFG) pelas análises de Fluorescência de raios X, e ao Conselho Nacional de Desenvolvimento Científico e Tecnológico (CNPq) pelo apoio financeiro.

\section{Referências bibliográficas}

Alkmim F.F., Brito Neves B.B. \& Castro Alves J.A. 1993. Arcabouço tectônico do Cráton do São Francisco: uma revisão. In: J. M. L. Dominguez, A. Misi (Ed.). O Cráton do São Francisco. SBG/ SGM/CNPq, Salvador, p. 45-62.

Alkmin, F.F. \& Martins-Neto, M.A. 2001. A Bacia
Intracratônica do São Francisco: arcabouço estrutural e cenários evolutivos. In: C. P. Pinto e M. A. Martins-Neto (Ed.). Bacia do São Francisco: geologia e recursos naturais. Sociedade Brasileira de Geociências-MG, Belo Horizonte, p. 9-30.

Alvarenga, C.J.S. \& Dardenne, A. 1978. Geologia dos grupos Bambuí e Paranoá, na Serra de São Domingos, MG. In: CONGRESSO BRASILEIRO DE GEOLOGIA, 30., 1978, Recife. Anais... Recife, SBG, v. 2, p. 546-556.

Campos, L.F.B. 2012. Diagênese de Sequências Proterozóicas com base na caracterização de argilominerais-topo do Grupo Paranoá e base do Grupo Bambuí-Norte do Distrito Federal. Brasília, 133p. Dissertação de Mestrado, Programa de Pós-graduação em Geociências, Instituto de Geociências, Universidade de Brasília.

Campos, L.F.B. \& Guimarães, E.M. 2017. Caracterização química de pelitos das formações Serra de Santa Helena e Serra da Saudade, Grupo Bambuí. In: CONGRESSO BRASILEIRO DE GEOQUÍMICA, 16., 2017, Armação de Búzios. Anais... Armação de Búzios, SBGQ. Disponível em: < http://www.sbgq. org.br/index.php?option=com_phocadownl oad\&view=category\&id=112:xvi-congressobrasileiro-de-geoquimica-litogeoquimica $>$. Acesso em: 31 out. 2017.

Campos, L.F.B., Guimarães, E.M., Barroso, R.H.G. \& Gomes, A.W. 2015. Cristalinidade da illita para indicar influência do esforço tectônico em Seqüências Proterozóicas no Distrito Federal e em Goiás, Brasil. Brazilian Journal of Geology, 45(3): 383-398.

Costa Neto, S.F. 2006. Ritmito Superior do Grupo Paranoá e fim da deposição na margem passiva. Brasília, 109p. Dissertação de Mestrado, Programa de Pós-graduação em Geociências, Instituto de Geociências, Universidade de Brasília.

Cox, R., Lowe D.R. \& Cullers, R.L. 1995. The influence of sediment recycling and basement composition on evolution of mudrock chemistry in the southwestern United States. Geochimica et Cosmochimica Acta, 59(4): 2919-2940.

Dardenne, M.A. 1978. Síntese sobre a estratigrafia do Grupo Bambuí no Brasil Central. In: 
CONGRESSO BRASILEIRO DE GEOLOGIA, 30. 1978, Recife. Anais... Recife, SBG, v. 2, p. $597-$ 610.

Dardenne, M.A. 2000. The Brasília fold belt. In: Cordani U. G., Milani E. J., Thomaz Filho A., Campos D. A. (Ed.). Tectonic Evolution of South America. INTERNATIONAL GEOLOGICAL CONGRESS, 31., 2000, Rio de Janeiro, SBG, p. 231-236.

Dardenne, M.A., Pimentel, M.M. \& Alvarenga, C.J.S. 2003. Provenance of conglomerates of the Bambuí, Jequitaí, Vazante and Ibiá Groups: Implications for the evolution of The Brasília Belt. In: SIMPÓSIO NACIONAL DE ESTUDOS TECTÔNICOS, 9., 2003, Armação dos Búzios. Boletim de resumos... Armação dos Búzios, p. 47-49.

Deer, W.A., Howie, R.A. \& Zussman, J. (Ed.), 1992. Minerais constituintes das rochas-Uma introdução. Fundação Calouste Gulbenkian (editora), Carlos António Regêncio Macedo (tradução), Lisboa, 727 p.

Freitas-Silva, F.H. \& Dardenne, M.A. 1994. Proposta de subdivisão formal para o Grupo Canastra no oeste de Minas Gerais e leste de Goiás. In: SIMPÓSIO DE GEOLOGIA DO CENTRO-OESTE, 4, Anais... Brasília, SBG, p. 161-163.

Fuck, R.A. 1994. A Faixa Brasília e a compartimentação tectônica da Província Tocantins. In: SIMPÓSIO DE GEOLOGIA DO CENTRO-OESTE, 4., 1994, Brasília. Anais... Brasília, SBG, p. 184-187.

Fuck, R.A., Pimentel, M.M. \& Silva, L.J.H.D. 1994. Compartimentação tectônica na porção oriental da Província Tocantins. In: CONGRESSO BRASILEIRO DE GEOLOGIA, 38., 1994. Balenário Camboriú. Anais... Balneário Camboriú, SBG, p. 215-216.

Guimarães, E.M. 1997. Estudos de proveniência e diagênese com ênfase na caracterização dos filossilicatos dos grupos Paranoá e Bambuí, na região de Bezerra-Cabeceiras (GO). Brasília, 270p. Tese de Doutorado, Programa de Pósgraduação em Geociências, Instituto de Geociências, Universidade de Brasília.

Guimarães, E.M. \& Dardenne, M.A. 2005. Glauconitas do Grupo Paranoá: Condições de deposição e contexto tectônico. In: SIMPÓSIO
SOBRE O CRÁTON SÃO FRANCISCO, 3., 2005, Salvador. Short papers... Salvador, SBG, p. 135138.

Guimarães, E.M., Dardenne, M.A. \& Tonietto, S.N. 2004. Primeiros registros da emersão do Orógeno da FDB em Goiás: Formação Serra de Santa Helena. In: CONGRESSO BRASILEIRO DE GEOLOGIA, 42., 2004, Araxá. Anais... Araxá, SBG, disponível em: http://www.sbgeo.org.br/ home/pages/44. Acesso em: 31 out. 2017.

Guimarães, E.M. \& Dardenne, M.A. 2005. Glauconitas do Grupo Paranoá: Condições de deposição e contexto tectônico. In: SIMPÓSIO SOBRE O CRÁTON SÃO FRANCISCO, 3., 2005, Salvador. Short papers... Salvador, SBG, p. 135138.

Laranjeira, N.P.F. \& Dardenne, M.A. 1993. Litoestratigrafia do Grupo Paranoá na região de Unaí, MG. In: SIMPÓSIO DO CRÁTON SÃO FRANCISCO, 2., 1993, Salvador. Anais... Salvador, SBG, p. 295-297.

Lima O.N.B. 2005. Grupo Bambuí: Estratigrafia regional no Alto Rio São Francisco e geologia dos depósitos fosfáticos da Serra da Saudade - MG. Belo Horizonte, 142p. Dissertação de Mestrado, Instituto de Geociências, Universidade Federal de Minas Gerais.

Lima, O.N.B., Uhlein, A. \& Britto, W. 2007. Estratigrafia do Grupo Bambuí na Serra da Saudade e geologia do depósito fosfático de Cedro do Abaeté, Minas Gerais. Revista Brasileira de Geociências, 37(4 - suplemento): 204-215.

Moreira, D.S, Uhlein, A., Fernandes, M.L.S., Mizusaki, A.M., Galéry, R. \& Delbem, I.B. 2016. Estratigrafia, petrografia e mineralização de potássio em siltitos verdesdo Grupo Bambuí na região de São Gotardo, Minas Gerais. Geociências, 35(2): 157-171.

Petrelli, M., Poli, G., Perugini, D. \& Peccerillo, A. 2005. Petrograph: a New Software to Visualize, Model, and Present Geochemical Data in Igneous Petrology. Geochemistry, Geophysics, Geosystems, 6(7): 1-15.

Pettijohn, F.J., Potter, P.E. \& Siever, R. 1987. Petrography of Common Sands and Sandstones. In: Pettijohn, F. J., Potter, P. E., Siever, R. Sands and Sandstones. $2^{\mathrm{a}}$ Edition. Berlim, Springer. 
$618 p$.

Pimentel, M.M., Dardenne, M.A., Fuck, R.A., Viana, M.G., Junges, S.L., Fischel, D.P., Seer, H.J. \& Dantas, E.L. 2001. Nd isotopes and the provenance of detrital sediments of the Neoproterozoic Brasília Belt, central Brazil. Journal of South American Earth Sciences, 14: 571-585.

Pinto, C.P. \& Silva, M.A. 2014. Mapa Geológico do Estado de Minas Gerais. Programa Geologia do Brasil, Integração, Atualização e Difusão de Dados da Geologia do Brasil-Projeto Mapas Geológicos Estaduais. CPRM e CODEMIG. Disponível em http://www.portalgeologia.com. br/mapa/, acessado em outubro de 2015.

Sampaio, L.F. 2016. Contexto deposicional $e$ diagênese de rochas Neoproterozóicas (Formação Serra Santa Helena) a partir da composição e Índice de Kübler: influência da moagem das amostras. Brasília, 66p. Dissertação de Mestrado, Programa de Pós-graduação em Geociências, Instituto de Geociências, Universidade de Brasília.

Valeriano, C.M., Dardenne, M.A., Fonseca, M.A., Simões, L.S.A. \& Seer, H.J. 2004. A evolução tectônica da Faixa Brasília. In: MANTESSONETO, V. (org.) 2004. Geologia do continente sulamericano: Evolução da obra de Fernando Flávio Marques de Almeida. São Paulo, 647p.

Whitney, D.L. \& Evans, B.W. 2010. Abbreviations for names of rock-forming minerals. American Mineralogist, 95: 185-187. 